\title{
Efectos de la crisis económica en la producción de contenidos de ficción televisiva en España entre 2010 y 2015
}

\section{Krisi ekonomikoak 2010. eta 2015. urteen artean Espainiako telebistako fikzio-edukiak ekoizteko orduan izan dituen ondorioak}

\author{
The Effects of the Economic Crisis \\ on the Production of Fiction TV Contents \\ in Spain between 2010 and 2015
}

\section{Mario García De Castro' Carmen Caffarel Serra ${ }^{2}$}

\section{zer}

Vol. 21 - Núm. 40

ISSN: $1137-1102$

e-ISSN: $1989-631 \mathrm{X}$

DOI: $10.1387 /$ zer. 15513

pp. 177-193

2016

Recibido el 19 de febrero de 2016, aceptado el 25 de abril de 2016.

\section{Resumen}

El objeto de estudio es la ficción nacional entendida como género paradigmático de la producción de contenidos de la programación televisiva. A través de su análisis se repasan las consecuencias que la crisis económica ha tenido para la producción y la creación de ficción: el envejecimiento del público del prime time, el fracaso de la televisión de pago, el predominio del duopolio privado, los recortes de las inversiones, la asfixia de las televisiones públicas, son algunos de los efectos de la crisis. Todo ello ha producido un retroceso en la calidad de contenidos y en hábitos de consumo.

Palabras clave: Ficción televisiva, programación, crisis económica, audiencia, producción nacional.

\footnotetext{
Universidad Rey Juan Carlos, mario.decastro@urjc.es

2 Universidad Rey Juan Carlos, carmen.caffarel@urjc.es
} 


\title{
Laburpena
}

Azterketa honen xedea fikzio nazionala da, telebistako programazioko edukien ekoizpenaren genero paradigmatiko gisa ulertuta. Azterketaren bidez, krisi ekonomikoak fikzioa ekoitzi eta sortzeko orduan izan dituen ondorioak berrikusi dira. Krisiaren ondorioetako batzuk hauek dira: "Prime time" ordutegiko publikoaren zahartzea, ordainpeko telebistaren porrota, duopolio pribatuaren nagusitasuna, inbertsioen murrizketak eta telebista publikoen asfixia, besteak beste. Horrek guztiak nolabaiteko atzerakada eragin du edukien kalitatean eta kontsumo-ohituretan.

Gako-hitzak: Telebistako fikzioa, programazioa, krisi ekonomikoa, ikusleak, ekoizpen nazionala.

\begin{abstract}
In the following research we analyze the television series of Spanish fiction, since this kind of show is special in television programming. Through this analysis, we can study the consequences the economic crisis in 2008 in Spain, had for the television industry, in general, and on the production of dramas, in particular. The aging of the, the failure of pay-tv in Spain, the predominance of the duopoly of two private companies, the financial cuts in investment, the suffocation of public television stations, are some of these implications of the crisis. All this has provoked a big regression of the quality in the offer of contents of television programs and also the consumption habits of TV viewers in this country.
\end{abstract}

Keywords: Television fiction, economical crisis, audience tv, spanish production. 


\section{Introducción y metodologías de estudio}

El objeto de estudio de este trabajo es la ficción televisiva de producción nacional entendida como género paradigmático de la oferta de la programación televisiva. El trabajo se centra en analizar si la crisis económica y social, desencadenada en España a partir del año 2008, ha tenido consecuencias para el sector televisivo en general y en concreto para la producción y la creación de la ficción doméstica serial. Por tanto, nuestro objeto de estudio se referirá a contenidos de ficción emitidos en horario de prime time, entre el 2010 y el 2015.

Las hipótesis manejadas en nuestro planteamiento se basan en que la repercusión de la crisis, con los recortes presupuestarios en las industrias culturales y creativas, también ha provocado que el sector audiovisual viviera los efectos de la caída de las inversiones y consecuentemente del talento sobre el que se desarrollan. Además de los cierres de empresas y empleos, que no son objeto de este análisis, el sector de la creación de contenidos audiovisuales ha sufrido un drástico retroceso tanto de la calidad de la oferta de contenidos como en los propios hábitos de consumo de los espectadores.

El análisis de la recepción, y del perfil social del público espectador, a través de los estudios de audiencias de las últimas temporadas, nos proporciona indicadores de las tendencias en los hábitos de consumo televisivo generalista, que se ha producido en el público de la televisión en España durante los años analizados.

En el terreno de la industria audiovisual, analizamos esas repercusiones por el retroceso de la multiplicación de la oferta televisiva que se inició con la puesta en marcha de la Televisión Digital Terrestre a partir del 2010 y en el regreso del predominio televisivo del duopolio generalista, y por otro lado en la crisis sufrida por las cadenas públicas y el retroceso del sector de la televisión de pago.

A continuación, y dentro de los análisis de las narraciones seriales contemporáneas, de la denominada neoserialidad o nueva serialidad televisiva (Innocenti y Pescatore, 2011), desarrollamos un análisis cualitativo comparado entre los contenidos locales y los internacionales. Para ello escogemos como referencia algunas de las series más vanguardistas o innovadoras de la televisión de pago en Estados Unidos, y de las cadenas públicas en el norte de Europa, durante los mismos años, siguiendo los criterios que utilizó Robert Thomson (1996) para definir la televisión de calidad, y a los que hace referencia Cascajosa (2006): "Los dramas de HBO reúnen con facilidad once de las doce características con las que Robert Thompson ha definido la televisión de calidad surgida en la década de los ochenta, entre ellas una que sirve de resumen a las demás: No es televisión convencional". De este modo definiremos las características que adopta este retroceso histórico de la industria televisiva española, en contraste con las tendencias internacionales innovadoras que han vivido en paralelo los contenidos de televisión tanto en Estado Unidos como en Europa en ese tiempo (Ros, 2011; Diego y Grandío, 2011).

Analizaremos las causas de nuestra hipótesis de "empobrecimiento y homogenización" de la oferta televisiva española y del gran déficit de innovación y modernidad en la creación de contenidos de ficción.

En definitiva, en el siguiente trabajo nos hemos planteado averiguar cuáles son los efectos de la crisis y su repercusión en los contenidos de la ficción televisiva, en los hábitos de consumo de las audiencias, en los cambios vividos por el sector industrial en 
sus sistemas de producción, en las distancias entre los contenidos locales y los internacionales, y también en el propio proceso creativo de la narratividad de dichos contenidos.

El análisis de la innovación o la calidad en la ficción televisiva puede comprobarse, entre otros criterios de evaluación, a través del estudio cuantitativo de los datos de audiencias de los programas analizados y del perfil de ese público que de ellos se obtiene (Gutiérrez, 2000), y contrastarlo con la percepción de esa calidad o renovación de los contenidos que perciben los propios profesionales del sector (Diego, Etayo y Pardo 2011). Por ello desde el punto de vista metodológico para lograr conocer estos objetivos tenemos que recurrir a la triangulación (Denzin, 1989) basándonos, por un lado, en los análisis empíricos a partir de los estudios de audiencias de la televisión en España y, desde el punto de vista cualitativo, a las interpretaciones de tendencias apuntados por las consultoras y profesionales del sector industrial de la televisión sobre esos datos. A los resultados obtenidos añadimos los análisis de contenidos de las series estrenadas entre el 2010 y el 2015 en España y el estudio comparado con las tendencias y contenidos de las series de ficción extranjeras más innovadoras en sus planteamientos, producidas en el mismo periodo.

\section{Perfil del espectador español}

Aplicamos el análisis de recepción para conocer los procesos que determinan los modelos de consumo (Morley, 1996). Estos estudios de recepción permitieron conocer hace décadas la relación entre audiencias e identidad cultural (Silverstone, 1996). El resultado de estos análisis empíricos sobre la audiencia de televisión permitió conocer la relación entre el perfil del público espectador y los grados de innovación o de calidad en la creación de nuevos contenidos televisivos (Thompson, 1996).

Por ello empezamos por identificar el perfil social del telespectador español y su evolución en los últimos años, según el porcentaje que representa cada target sobre el consumo televisivo. El consumo de televisión en nuestro país, según los datos del muestreo para el control de audiencias que aplica en España Kantar Media, está repartido en general entre un $51,4 \%$ de público femenino y el 48,6\% de público masculino, mientras que esta proporción de audiencia resulta a la inversa en otros medios de comunicación como son la radio, el cine o internet. Tradicionalmente el perfil de edad del público español de televisión en el horario de prime time, está sostenido por el público de mayor edad: un 55,2\% entre 45 y más de 64 años, y un 41,8\% entre 13 a 44 años. Según datos de la Asociación para la Investigación de Medios de Comunicación (AIMC) del $2014^{3}$, el peso en el total del consumo de televisión de los mayores de 65 años es de 22,1 \% y de los de 45 a 64 años el 31,8\%, en ligera tendencia de crecimiento respecto al año anterior. También el último informe "Análisis Televisivo 2014"4 elaborado por la consultora Barlovento Comunicación, basándose en datos del control de audiencias en España de Kantar Media, confirma que los individuos de más de 45 años y 64, y las mujeres, son los que más tiempo han dedicado a ver televisión en los años analizados en España.

\footnotetext{
Marco General de los Medios en España 2015. Perfil de la Audiencia de los Medios en España. 2014. Asociación para la Investigación de Medios de Comunicación. AIMC. http://www.aimc.es/-Marco-General-.html

4 Barlovento Comunicación, con datos de las audiencias de Kantar Media.02/01/2015. http://www. barloventocomunicacion .es/images/publicaciones/analisis-televisivo-2014-Barlovento.pdf
} 
Analizando los datos históricos sobre el perfil del espectador se observa un predominio del colectivo denominado "tradicional", es decir, compuesto por mayores de 45 años con preferencias conservadoras respecto a los contenidos, principalmente mujeres de estatus medio, que se decantan por las historias más emotivas. Por otra parte, también las series de ficción españolas históricamente han tenido un perfil fundamentalmente femenino, aunque esta determinación se fue equilibrando en algunas ocasiones con las series de contenidos juveniles o profesionales, producidas hace ya más de diez años (García de Castro, 2012). Por entonces había comenzado a crecer en el prime time el nuevo perfil del aficionado a la ficción televisiva, que era el de 30 a 45 años, de ambos sexos y entorno urbano. Perfil que en los últimos años ha ido perdido peso, como puede comprobarse en los datos de audiencias obtenidos por Kantar Media, al decantarse, este público, por el consumo de otras pantallas. Contrariamente a esta tendencia, las series de intriga, que son las que más han triunfado en las temporadas televisivas de la crisis, han mostrado el proceso de reafirmación del público femenino como principal variante del perfil del público de la ficción nacional.

De hecho, Gran Hotel (A3. 2011) es la serie española que ha aglutinado a mayor número de espectadoras de los últimos años según el estudio del Gabinete de Estudios de Comunicación Audiovisual (GECA) sobre ficción realizado en $2013^{5}$. Esas series, Herederos (TVE. 2007), Gran Reserva (TVE. 2010) o Gran Hotel (A3. 2011), son series de "intrigas sentimentales" que han incrementado el porcentaje de público femenino en su consumo durante su emisión, como también las series de "comedia de vecinos" como Aquí no hay quien viva (T5. 2005), La que se avecina (T5.2010) o Con el culo al aire (A3.2011), ejemplos de series con mayor porcentaje de público femenino, como puede observarse en la Figura 1.

Figura 1. Perfil por sexo de la ficción nacional de prime time.

Series históricas

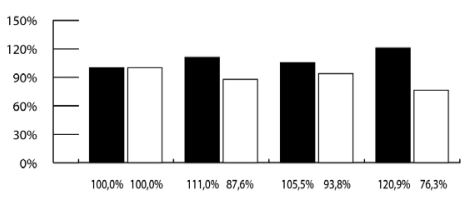

Series policías

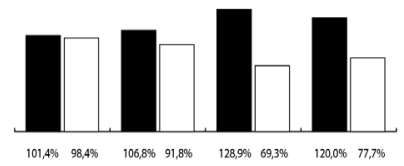

Series profesionales

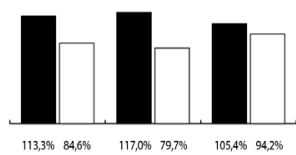

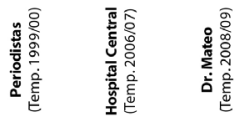

Mujeres $\quad \square$ Hombres

Fuente: Elaboración propia a partir de los datos de Geca.

\footnotetext{
5 "El perfil de las series españolas de prime time". Periodo de análisis: temporadas 1998/99 a 2011/2012. Geca/Globomedia. Madrid, 2013, y donde se analiza el público de las series españolas emitidas entre dichas temporadas 98/99 y 2011/12 sobre los datos de audiencias de Kantar Media a través de su panel de audímetros.
} 
Esta especificación en un sector tan influido por los resultados del control y los estudios de audiencias, que ajustan como un guante la oferta a la demanda, y un debilitado sector de la creación de ficción serial nacional, ya apuntan, junto al resto de factores que analizaremos a continuación, lo que podemos llamar el retroceso creativo que vive actualmente la ficción televisiva nacional. Como veremos más adelante, las tendencias internacionales de los contenidos más vanguardistas de ficción serial televisiva, tanto en las cadenas públicas como en las televisiones de pago americanas o europeas, equilibran más su distribución por sexos en el perfil de su público.

\subsection{Hábitos de consumo de las series españolas}

Durante este quinquenio de la crisis, la oferta de contenidos de las cadenas generalistas y en abierto en España se ha mantenido determinada por el sistema que regula el mercado, es decir, el sistema de control de audiencias basado en el número de espectadores totales, que sigue midiéndose cuantitativamente por el share y la ratio, y donde el peso del perfil del público es subsidiario ${ }^{6}$. A pesar de las demandas de anunciantes, las centrales de planificación de medios siguieron subvalorando la contratación de GRPs (Gross Rating Points), por targets de público, lo que impidió el desarrollo de contenidos más orientados y específicos.

Para analizar los tipos de consumo de series de ficción en España nos hemos basado en las conclusiones que presenta el estudio "El perfil de las series españolas de prime time" realizado por el Gabinete de Estudios de Comunicación Audiovisual (GECA), sobre los datos de audiencias de Kantar Media, y donde se analiza el público de las series españolas emitidas entre las temporadas 98/99 y 2011/12. Sus resultados concluyen que, a diferencia de otros contenidos que favorecen un consumo más individual, las series de ficción tienden a un consumo más grupal, incluso a pesar de que su planteamiento u orientación busque la segmentación, como puede verse en la Figura 2.

Figura 2. Perfil según tipo de visionado comparando realities con series.

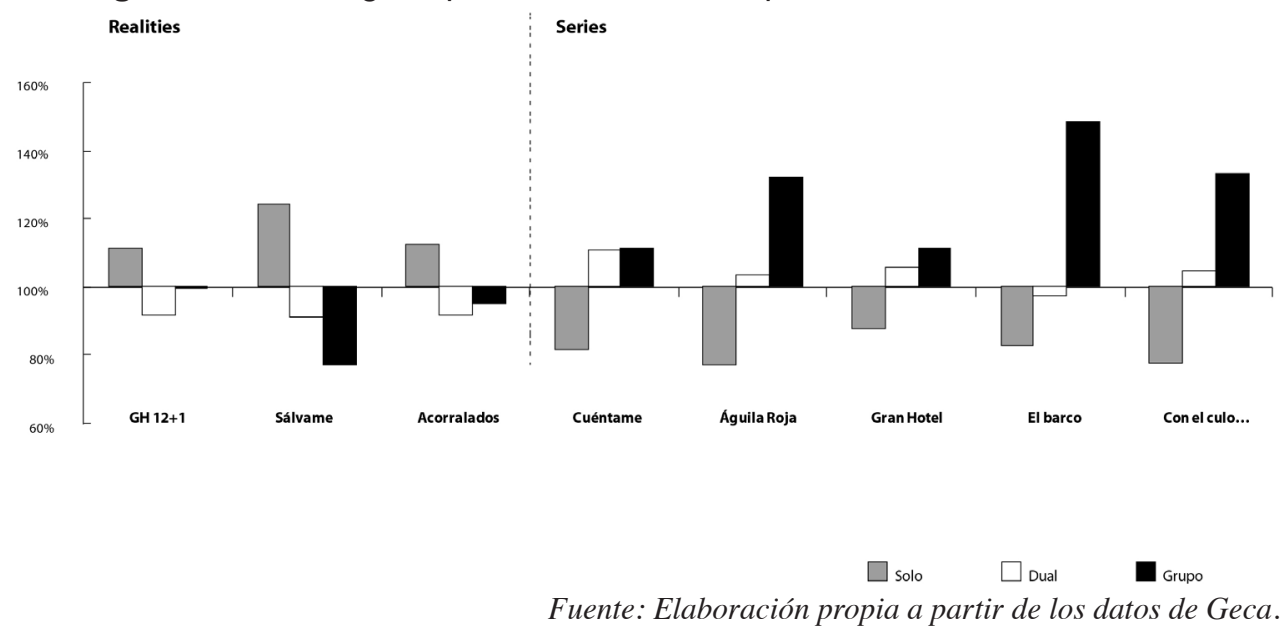

\footnotetext{
${ }^{6}$ Medición de audiencias en España de la empresa Kantar Media a través de su panel de audímetros.
} 
El modelo de televisión generalista tradicional en España está basado en el consumo familiar o grupal, condicionando de este modo sus contenidos. Sin embargo, es la televisión temática o de pago la que más ha cambiado los hábitos de consumo de los contenidos de la televisión, con su riqueza y pluralidad de oferta, y su adaptación a los horarios y preferencias de los diferentes públicos, segmentando así su orientación.

Más en concreto, los resultados del estudio de GECA del 2013 indican que solo las series adolescentes, como Física y Química (A3. 2008-11), que presentaron un perfil de público mayoritario de entre 13 a 24 años durante sus emisiones en Antena3 en las temporadas 2010-2011, alcanzaban porcentajes de casi el 40\% de consumo a solas. Esto es fundamentalmente porque son contenidos de adolescentes que prefieren no compartir con los adultos.

Además, el estudio de GECA destaca que las series en general heredan el sentido del perfil de la cadena. De este modo Águila Roja (TVE. 2009-), aunque tenga una orientación juvenil, hereda el perfil adulto de su cadena de emisión TVE y alcanza un $26,2 \%$ de consumo grupal. Este resultado supone el consumo grupal más fuerte de la ficción nacional. Algo parecido ocurre con cadenas como Telecinco, que es la otra oferta televisiva con fuerte perfil adulto, y los datos arrojados por esta investigación con Hospital Central (T5.2000-12), y sus 20 temporadas.

Sin embargo, son los programas de corazón o crónica rosa y los realities los que suelen presentar un consumo más individual. Telecinco es el canal que presenta un consumo más individual. Gran Hermano (T5. 2004-), con un perfil de edades entre 13 a 45 años, o Sálvame de Luxe (T5. 2009), con un perfil de 45 años en adelante, presentan consumos individuales muy superiores a los del Total Televisión (TOTV), como pudimos ver en la Figura 2, en tanto que las series españolas no presentan consumos individuales, no suelen verse a solas, como los realities, con independencia del perfil de edad de su público.

La proporcionalidad de público dependiendo de otros criterios demográficos como el hábitat también es sobresaliente, según los datos del estudio "El perfil de las series españolas de prime time" (GECA). Según la población o tamaño del hábitat, la serie 7 Vidas (T5. 1999-2006) presentaba un notable consumo en núcleos de más de 50.000 habitantes, y las series profesionales fueron las que mostraron un perfil urbano, en núcleos de más de 500.000 habitantes, más acusado que en otros tipos de series.

Por tipos de hogares, las series juveniles se consumen preferentemente en hogares monoparentales o de parejas con hijos adolescentes. De igual modo que las profesionales o las policiacas, destacan fundamentalmente en hogares monoparentales, las comedias populares se consumen preferentemente en hogares de parejas jóvenes sin hijos o con hijos pequeños. Mientras que las series sentimentales de intrigas, series que han gozado de mayor éxito en las últimas temporadas, triunfan en hogares de adultos sin hijos y personas mayores de 65 años.

Estos son los rasgos más convencionales que perfilan el público de prime time de la televisión generalista o en abierto y que se afianzaron en los años de la crisis.

Queda lejos el final de las series innovadoras de la primera década del nuevo siglo. El Barco (A3. 2011), una serie de drama, misterio y ciencia ficción, con un perfil de público menor de 45 años, duró tres temporadas que fueron decayendo del $20 \%$ al $14 \%$ de share. Otras dos series de esa misma cadena, innovadoras y orientadas a los jóvenes como Los protegidos (A3. 2010-12) o El Internado (A3. 2007-10), ya habían 
corrido una suerte parecida. Los protegidos, una serie de drama y fantasía, concluyó tras disminuir del 18 al $12 \%$ de share. Son ejemplos de series orientadas a encontrar un público joven que fracasaron rápidamente en su intento.

\section{Crisis creativa y esfuerzo de producción}

Los contenidos de las series reseñadas en el quinquenio analizado confirman, como veremos en el epígrafe 4, que sus señas de identidad siguen basándose en los siguientes rasgos, la mayoría de los cuales ya estaban vigentes en el quinquenio del 95 al 2000 (García de Castro, 2002):

- Neorrealismo y naturalismo local de personajes e historias.

- Personajes convencionales y locales.

- Reparto de roles y conductas estereotipadas por género, edad o clase social.

- Tramas afectivas y románticas orientadas a la emotividad.

- Facilidad de valoraciones morales de las actividades de los personajes protagonistas.

Sin embargo, hay que reseñar que existió una superación de los estándares de producción en los últimos años en la puesta en escena y en la dirección de arte. Los rodajes y la fotografía destacan en su calidad como consecuencia del uso de los avances tecnológicos audiovisuales que se han producido en los últimos años. La mejora en la calidad audiovisual, generada por los procesos de digitalización de las nuevas tecnologías, tanto en la grabación como en la composición o en la reproducción, han propiciado que la factura audiovisual de las series nacionales haya madurado y crecido drásticamente, aportando un sello internacional a buena parte de los éxitos de la ficción televisiva nacional de las últimas temporadas. A pesar de la crisis económica, con la consecuente reducción de inversiones y de presupuestos para la producción de ficción, se han mantenido las grabaciones en exteriores y su efecto cinematográfico en el formato.

En nuestro análisis debemos valorar la distancia entre las características de la creatividad de la ficción televisiva nacional y las tendencias internacionales. Una distancia que se agranda de modo abismal en estas últimas temporadas de la crisis, mientras que hubo otras etapas en las que se habían aproximado por imitación (Canovaca, 2011), o en algunas series de comedia, en las que la creatividad había innovado decisivamente (Grandio y Diego, 2009).

Para ello nos hemos basado en la evolución de los contenidos y sus formas de representación de la ficción televisiva internacional, a través del análisis cualitativo de series dramáticas anglosajonas o europeas, que más adelante mencionamos. Procedentes en algunos casos de canales de televisión de pago por cable o satélite norteamericanas, como los canales HBO o Netflix, o de televisiones públicas europeas como la BBC o las cadenas escandinavas, que es donde se localizan los productos más innovadores, como hemos señalado.

Esta evolución se plasma en el uso frecuente de parámetros de innovación argumental (Thomspson, 1996), que, en nuestro análisis de contenidos, hemos basado en las siguientes características: 
- Personajes muy complejos pero universales y referenciales (Don Draper de Man Men. AMC 2007-15).

- Personajes alternativos psicológicamente que evolucionan con el desarrollo de las temporadas (Carrie de Homeland. Showtime. 2011-).

- Difusa connotación moral de las acciones de los personajes, al diluirse los límites entre el bien y el mal, así como los juicios de intenciones o los prejuicios en las historias (True Detective. HBO 2014).

- Tramas que no valoran o cuestionan moralmente situaciones de la vida de esos personajes protagonistas (Breaking Bad. AMC 2008-14) .

- Sobreutilización de tramas de intriga y thriller (Bron. SVT 2011 y Broadchurch ITV 2013).

- Uso de nuevos giros durante las tramas, inusuales en la estructura narrativa clásica (Borgen, DR 2010-13 y House of Card, Netflix 2013).

Mientras que este tipo de series dramáticas han afianzado en los últimos años la hegemonía internacional de la ficción televisiva en la producción creativa del audiovisual (Cascajosa, 2005), en nuestro país se ha producido un fenómeno inverso. La imagen de crisis creativa en la ficción española se trasmite desde hace varias temporadas, cuando críticos y analistas empezaron a apreciar ausencia o déficit de novedades destacadas en los estrenos de las nuevas series. El desgaste producido por el exceso de repetición de planteamientos en los contenidos de historias y personajes ha propiciado esa pérdida de empuje y originalidad en el género de ficción dentro de la programación televisiva.

\subsection{Crisis de la televisión de pago}

Según los datos de la Comisión Nacional de los Mercados y la Competencia (CNMC), durante los años de la crisis las plataformas de la televisión de pago españolas sufrieron unas pérdidas de cerca de 700.000 usuarios $^{7}$. Datos que indican un retroceso considerable de esta oferta televisiva a nivel español, pero que contrasta con los resultados de otros países, donde la televisión de pago solo ha hecho que crecer en el número de usuarios. La penetración de la televisión de pago en España ha descendido en el 2013 al 21,2\% mientras que en 2011 se situaba en el 21,9\%, según datos de la CNMC. Actualmente en manos de las empresas de telecomunicaciones, sus nuevos responsables planifican un crecimiento de los usuarios de la televisión de pago en España semejante al de otros países, y a partir del 2015 esta ventana ha vuelto a crecer tras años de estancamiento ${ }^{8}$.

Desde el 2007, fecha que registró el record de facturación publicitaria por las cadenas, el descenso de la inversión publicitaria en el sector de televisión fue imparable hasta el año 2014, desde el que primero se estabilizó y después comenzó a remontar, aunque el modelo actual de la publicidad de los GRPs, esté cuestionado

\footnotetext{
7 Nota Trimestral del sector audiovisual. $2^{\circ}$ Trimestre 2014. Estad/SG/0027/14. Comisión Nacional de los Mercados y la Competencia. http://www.cnmc.es/Portals/0/Ficheros/Telecomunicaciones/Informes/Nota_II_Trimestre_2014.pdf

8 Análisis televisivo 2015. BarloventoComunicación. Enero 2016. file://C:/Users/Mario/Desktop/TareasFebrero/analisis-televisivo-2015-Barlovento.pdf
} 
estructuralmente por los drásticos cambios en el consumo de televisión. Según los últimos estudios de mercado de las marcas comerciales interesadas, el consumo de vídeo en streaming -sistema que permite el consumo de vídeo en internet en paralelo a su descarga- está aproximándose cada vez más al de la televisión convencional (Ericsson Consumer Lab) ${ }^{9}$. Crece también el porcentaje, en algunos casos hasta el $75 \%$ de los telespectadores, de los que ven diariamente contenidos -películas, series o programas- en streaming, frente al $77 \%$ que lo hace en la televisión convencional.

La tendencia internacional que suscriben desde hace años los estudios de Nielsen, empresa estadounidense que lleva a cabo el control de audiencias en USA, indica que el consumo tradicional de televisión de los jóvenes se desmorona anualmente. Emerge un consumidor de ocio cada vez más tecnologizado y diferenciado (Álvarez y Menor, 2010). Las personas entre 18 y 25 años ven 5 horas menos de televisión a la semana, lo que representa 45 minutos menos al día. Hace varios años que se registran descensos en el consumo de televisión de los jóvenes, aunque la caída no sólo se centra en esta franja de edad. El consumo de vídeo online o a través de tabletas y teléfonos móviles surge como principal causa de esta caída del consumo. Sin embargo, en España, las diferencias entre televisión e internet continúan siendo abismales, y el streaming se presenta de momento en España como un complemento, más que un sustituto de la televisión.

En el caso español, Crematorio (Canal +. 2011), fue el primer intento de una de ficción producida por la televisión de pago para su estreno en una ventana cuyo planteamiento no estaba pegado al share de la audiencia. Pero también fue el último a pesar del éxito de crítica y público. El descenso de la televisión de pago en España durante los años de la crisis contrasta con las rentables experiencias de otros países de nuestro entorno como la plataforma Sky en Italia, Reino Unido o Francia, donde se supera el $40 \%$ de penetración. Recuérdese también como contraste, la experiencia de $\mathrm{HBO}$ en el desarrollo de la ficción serial estadounidense más innovadora (Cascajosa, 2006).

Lo que nos llevaría a concluir que, a día de hoy, el balance en España de la televisión de pago es insignificante respecto a la innovación de los contenidos, ni ha aportado la menor modernidad a la industria de la televisión nacional.

\subsection{Los recortes y la crisis de la televisión pública}

Los recortes económicos fueron directos responsables del retroceso. Los presupuestos de todas las series de prime time se redujeron en una media de un 33\%, según indican los productores y reconocen los emisores. Mientras que hace diez años se podía apostar por la calidad de un episodio de 70 minutos netos, si alcanzaba el liderazgo de audiencia, en más de 800.000 euros de presupuesto, hoy día la misma serie no superará difícilmente los 500.000 euros por ese episodio ${ }^{10}$. Con ello los salarios de la producción han decrecido y los medios y grabaciones han regresado a los platós.

Las cadenas optaron por la prudencia para encarar la crisis, sobre todo a la vista de fracasos como Vivo cantando (A3. 2013), Con el culo al aire (A3. 2012), He visto

\footnotetext{
9 TV and Media 2014, An Ericsson Consumer Insight Summary Report. September 2014

${ }^{10}$ Declaraciones realizadas en la entrevista personal realizada a Daniel Écija, Presidente de la productora Globomedia, el 15-12-2014
} 
un ángel (T5. 2014), o Familia (T5. 2013). El hecho es que, según el informe anual de Gabinete de Estudios de Comunicación Audiovisual (GECA) ya citado, la mayor parte de los estrenos de ficción del 2013 eran herederos de temporadas anteriores. El género más perjudicado por la tendencia general a la reducción de estrenos por cadenas desde el 2011 fue el de la ficción con un descenso del 44\% de estrenos menos que hace dos temporadas.

Como consecuencia de los recortes sociales, el gobierno valenciano decretó el cierre de la radiotelevisión valenciana que emitía desde el 1989. Con el cierre en 2013 de Canal 9, televisión autonómica de Valencia, parecía iniciarse el fin de televisiones públicas autonómicas en nuestro país. La misma suerte parecían correr otras televisiones autonómicas como Telemadrid, que se había convertido en una emisora sin contenidos de ficción propios y sin espectadores. Solo unos informativos progubernamentales se mantuvieron en la oferta de su producción propia. Conviene recordar que las televisiones públicas regionales habían sido, tanto en la década de los 90 como posteriormente, un elemento dinamizador de la industria de la ficción regional.

Sin embargo, el papel más innovador ha sido asumido en nuestro entorno europeo por las televisiones públicas, que constituyen auténticos motores de la innovación de la industria de contenidos audiovisuales y que han contribuido decisivamente a esta última renovación de la ficción serial. Bron o Broen (SVT1 y DR1.2011) de las televisiones públicas escandinavas, o también la danesa Borgen (DR1.2010), constituye un buen ejemplo. De algún modo también Utopía (Channel 4. 2013)

La necesidad de que las televisiones públicas se convirtieran en fuerza motriz del proceso de convergencia tecnológica en el nuevo entorno digital, entendida como nueva misión del servicio público (Medina y Ojer, 2011), también se paralizó con las primeras consecuencias de la crisis financiera. En nuestro país, la evolución de la televisión pública pareció derivar durante estos años en sentido inverso a esa tendencia general. Progresivamente asfixiada sin publicidad, con escasos recursos, se convierte en un lastre de manipulación y propagandismo gubernamental, que solo gracias a una dirección con autonomía editorial y profesionalizada pudo brevemente apostar por la ficción de calidad (Caffarel, 2013).

\section{Las tendencias internacionales}

De Twin Peaks a Lost se han sucedido muchas series en la crónica de la ficción y han cambiado muchos medios. Siguiendo los mismos criterios de calidad que definió Thompson en 1996: “...tienen pedigrí, atraen a una audiencia de clase media-alta, tienden a los repartos extensos, tienen memoria, apuestan por la hibridación de géneros, se centran en la figura del escritor, son auto-reflexivos, cuentan con temas controvertidos, aspiran al realismo y suelen ganar premios y otro tipo de reconocimientos de la crítica" (Cascajosa, 2006), podemos trazar una evolución de la innovación en la ficción serial internacional.

En Estados Unidos la primera muestra del cambio profundo de la industria de la ficción televisiva llego a partir del 2000 con David Chase, creador de Los Soprano (Cascajosa, 2007). Continúo dos años después con David Simon con The Wire, en el 2008 con Vince Gilligan y Breaking Bad, y llega al 2014 con Nic Pizzolatto con True Detective.(Pérez Gómez, 2011) Todo gracias a HBO, canal de cable, que decidió 
producir series dramáticas originales de una hora de duración. Con esta fórmula la televisión dejo de ser el electrodoméstico del tiempo libre para convertirse en el refugio del séptimo arte, como consecuencia de la producción de esta nueva ficción televisiva. Y hoy sucede con Netflix, que proporciona video on demand en streaming, bajo demanda por internet, y que aporta la nueva distribución de contenidos audiovisuales. El spotify del audiovisual ya ha dejado atrás cadenas como HBO para hacerse sitio entre corporaciones como Google, Amazon o Microsoft.

En Europa, durante estos años, fueron concretamente las televisiones públicas escandinavas las que lideraron un salto de la ficción serial televisiva al otorgar en su origen una gran libertad de planteamiento a sus creadores y facilitar recursos para su producción. La televisión pública danesa DR no se ha limitado a la producción de recreaciones históricas como 1864, en 2014, sino que alcanzó retratos políticoperiodísticos de gran actualidad como Borgen, en el 2010, en la que una mujer llega a primera ministra de su país.

\subsection{La nueva narrativa}

Las nuevas tendencias internacionales en la creación de series de ficción televisiva aportan contrastes con la situación española durante esos años. El perfil psicológico de los personajes protagonistas de las nuevas series, de los nuevos héroes o antihéroes, revela más novedades: son protagonistas infelices, bastante inmorales enfermos mentales o sociópatas. Protagonistas del drama que son traidores y delirantes, pero personajes profundamente humanos, que apelan a la implicación emocional del espectador, quien se deja seducir desde el principio por unos personajes frustrados por el mundo moderno. De ambos sexos, porque más allá de los varones, también aparecen personajes femeninos que podían ser corruptos o seres heroicos. Depresión, alcoholismo, bipolaridad, en definitiva, mala salud mental. Así son los protagonistas de esas nuevas series, como Carl Hiekmen de Crossing Lines (TF1, NBC, SAT1, 2013), Megan Boone de The Black List (NBC, 2013), Carrie de Homeland, Will de Hannibal (García-Martínez, 2012). Historias ambiguas y complicadas que no van a acabar bien, y que por primera vez rompen con todo lo visto hasta entonces, aquellos personajes estereotipados cuyo único objetivo era complacer al mayor número de audiencia media y a los anunciantes de la cadena.

Además del perfil heterodoxo de los personajes aparece una nueva estructura narrativa en los guiones (Innocenti y Pescatore, 2011). "No sólo se trataba de nuevas clases de historias, sino de que se narraba con un nuevo tipo de estructura formal", señala Brett Martin (2014) en Hombres Fuera de Serie. Así fue el desembarco, como señala Martin, de "los escritores de palabras que se expresan con imágenes" en el mundo de la televisión. Estos nuevos autores se muestran discípulos, por ejemplo, del neorrealismo italiano. Entonces cambia la forma de narrar en la ficción serial televisiva, porque aparece el autor, quien deja atrás el anonimato en el que había estado sumido en décadas anteriores, y la ficción televisiva se arroja en manos de la estética y la composición cinematográfica, de los planos cenitales de True Detective (HBO. 2014-) o los de cámara en tierra de Breaking Bad (AMC. 2008-14). Es la llamada "tercera edad dorada de la televisión", o más bien de un nuevo concepto de televisión impulsado por la nueva ficción y la nueva forma de consumo que se impone (Martin, 2014). 
Esto contrataba con el perfil de los personajes de los dramas nacionales, que siguió anclado sin detalles, en los roles estereotipados de bondadosos o malvados. Guionistas de nuestras series consideran que "todavía no ha nacido en España un personaje como el de Tony Soprano (Los Soprano), Walter White (Breaking Bad) o Don Draper (Mad Men)" 11 .

Tras la excepción de Crematorio (Tous. 2015), en nuestro país, una serie histórica sobre Isabel la Católica (TVE. 2012), fue la serie de mayor alcance político, en contraposición a las tan contemporáneas House of card (Netflix. 2013) o Borgen, o Águila Roja, tan inofensiva que parecía un humilde simulacro de Juego de Tronos (HBO. 2013-), aunque fuera la más seguida por el público joven de la historia de TVE.

\subsection{El contraste español}

Otra serie histórica, El Ministerio del tiempo (TVE.2015), fue la nueva apuesta por la calidad en el género fantástico y de aventuras. También en los indicadores de la salida de la crisis narrativa española se sitúa Bajo Sospecha (A3.2015), miniserie presentada como tendencia mundial y estrenada en Antena3, después del fracaso de Desaparecida (TVE. 2008). Su planteamiento alarga la intriga con una trama de thriller policiaco en la estela de la escandinava Bron, el Puente (SVT. 2011), o la británica Broadchurch (ITV. 2013), pero filtrado por el estilo casero (en su sustrato seguía latiendo la misma vocación de público familiar, que fuerza a estereotipar los personajes entre buenos y malos). La distancia entre nuestra ficción televisiva y la internacional la apreciamos también en esos intentos: mientras que, en Reino Unido, la serie, se mantiene con éxito desde el 2013, en España concluyó a las pocas semanas de su estreno. Otras series, como El tiempo entre costuras (A3. 2013), Gran Hotel (A3.2011-) y Velvet (A3. 2014), fueron las series de mayor factura visual, ambas respondiendo a la moda de las series de época que se acabó imponiendo en el retroceso histórico de la crisis, y a la vez que El Chiringuito de Pepe (T5. 2014-), la eterna corriente de la comedia española procedente de la popular La que se avecina (T5 2007).

Los sonados fracasos de audiencias de series innovadoras que intentaban emular los éxitos americanos localizándolos en series como El Barco o El Internado (Pérez Gómez, 2011), series que se exportaron al exterior mejor que se consumieron en España, según los datos de sus propios productores, en el paréntesis entre el 2007 y el 2010. Finalmente, El Príncipe (T5. 2014-) fue el nuevo intento más serio de imitar a las series dramáticas americanas. Intento que también procede de la cantera de $E l$ Comisario, con doce temporadas en Telecinco (1999-2009).

La pequeña industria audiovisual española ha regresado a los mismos resortes creativos de hace ahora casi dos décadas: el localismo de las historias y los personajes vinculadas a nuestras raíces y a nuestro entorno más referencial, que se inició con Médico de Familia de Globomedia en los años 90 (García de Castro, 2002) y que se renovó para seguir su continuidad en 7 vidas y después en Aida en los primeros años del 2000 (Diego, 2010).

El modelo no ha variado mucho, porque los creativos y productores de la ficción serial en España han vuelto a escribir para el mismo perfil de audiencias (Diego y

\footnotetext{
${ }^{11}$ Declaraciones realizadas en la entrevista personal realizada a Daniel Écija, Presidente de la productora Globomedia, el 15-12-2014.
} 
Grandío, 2011). Esos mismos resortes de localismo y referencialidad los reconocemos en la propia El tiempo entre costuras o El Príncipe.

\section{Discusión y conclusiones}

En España, los recortes de gasto de la crisis paralizaron el proceso de segmentación que parecía iniciar la implantación de la TDT gratuita en España. La caída de la inversión publicitaria contribuyó a consolidar la concentración y la tendencia hacia la homogeneización que se reforzó tras los años de crisis. Por primera vez en 2014, la suma de la cuota de mercado de las tres grandes cadenas, TVE, Telecinco y Antena 3 , es superior $(38,1 \%)$ a la del año anterior, es decir que incrementan su mercado. En general, por el predominio de los dos grandes grupos privados. Además, la cuota conjunta de estos grupos privados creció por tercer año consecutivo, mientras las temáticas, que nacieron con la TDT, decrecieron. En 2015 el duopolio privado ya suponía el $58 \%$ de la cuota del mercado y el $86 \%$ de la inversión publicitaria ${ }^{12}$.

Esta crisis lesionó a todos los contenidos en general de la televisión en España, provocó una parálisis en la creación, el conservadurismo de propuestas, la homogenización de contenidos y el low cost de la producción. El riesgo y la innovación casi desaparecieron.

La homogeneización de audiencias y oferta propiciada por la crisis paralizó la especialización de perfiles generacionales y la interactividad de la televisión. Esta crisis económica y social ha dejado un rastro de regresión y retroceso cultural y creativo también entre los desdichados telespectadores españoles. Pero en el mundo del streaming, la evolución tecnológica mundial para la distribución de los contenidos sigue desbocada, y hoy en día el antiguo modelo de la televisión de pago ya no representa la solución al retraso de nuestra televisión. Netflix, compañía de video en streaming, con 40 millones de suscriptores en 2014, ya ha dejado atrás la televisión por cable de $\mathrm{HBO}$, con 27 millones, en penetración de hogares en Estados Unidos ${ }^{13}$.

En estos momentos en España, el hábito de consumo individual de la televisión, a pesar de todos los datos anteriormente mostrados, también presenta un repunte, según el informe de la empresa Barlovento del 2015, y ficciones como El Príncipe o El Ministerio del Tiempo, suponen el mayor consumo de televisión en diferido. De igual modo sube unas décimas el consumo de la televisión de pago, por la oferta de Movistar, aunque aún solo representa un exiguo $6 \%$ de cuota de pantalla. En nuestro país, la caduca fórmula de la oferta de la televisión familiar aún ha seguido determinando el contenido de la oferta televisiva y sus limitaciones actuales, entre otras cosas porque el rendimiento publicitario siguió midiéndose en GRPs.

La crisis parece desencadenar también en la televisión en España una nueva transición, porque el futuro tecnológico resulta ineludible y las viejas cadenas deberán afrontar una nueva distribución de contenidos. Con las nuevas modalidades de relación creadas entre usuarios y medios, los cambios imparables acaban planteando nuevas plataformas de distribución. Esto incidirá directamente en los contenidos y también en las audiencias y sus hábitos de consumo (Innocenti y Pescatore, 2011). Porque finalmente el análisis alcanza a los cambios tecnológicos, y son los distribuidores los

\footnotetext{
${ }^{12}$ Barlovento Comunicación, con datos de Kantar Media.02/01/2015 y 02/01/2016.

${ }^{13}$ Citado en: http://www.etcetera.com.mx/articulo/netflix_cava_tumba_de_blockbuster/22503/
} 
que determinan el contenido. La tecnología es el modelo de la calidad. Por eso esta regresión analizada en el quinquenio de la crisis, solo es cultural, por tanto, efímera, y no tecnológica. La fragmentación de los públicos se consumará en el futuro (Álvarez y Menor, 2010).

En resumen, el análisis de este retroceso creativo de la ficción televisiva española nos ha hecho concluir que las causas han sido las siguientes:

- $\quad$ El envejecimiento del público de prime time de la ficción televisiva.

- La desfragmentación de la oferta iniciada con la TDT.

- La consolidación del predominio el duopolio generalista.

- La crisis del sector de la televisión de pago.

- $\quad$ El recorte en la inversión de las cadenas por la crisis.

- La debilidad o asfixia de las televisiones públicas.

- El retroceso creativo en la producción de los contenidos.

Durante los años analizados, se consolidó el duopolio audiovisual privado en nuestro país, tras el espejismo de la TDT, la televisión pública pareció precipitada hacia su desaparición, y decayó por crisis empresarial la televisión de pago. También la ficción televisiva nacional vivió la regresión creativa mayor de toda su historia reciente, como demuestra el envejecimiento de la audiencia y el retroceso hacia tendencias más tradicionales de los hábitos de consumo de televisión. Las expectativas que surgieron a partir del 2007 con intentos de innovación de contenidos que exploraron la ciencia-ficción o las historias de época, y que parecían iniciar un cambio de tendencia (García de Castro, 2015), no se han correspondido finalmente con la renovación de la creatividad que experimentó la ficción internacional, a pesar de la crisis mundial.

La ficción televisiva española no le concede precisamente hoy a la televisión su edad de oro. Eso es cosa de otros países y de otros mercados, desde luego de EEUU y del sector de la televisión de pago, o de la televisión pública en Europa. Mientras que internacionalmente el consumo de las series de televisión ha evolucionado drásticamente y a gran velocidad por parte del público joven, en España parece haber retrocedido como consecuencia del predominio del tradicional target generalista, del sistema de rentabilidad publicitaria de los GRPs y directamente de la crisis y recortes de los gastos de inversión. Pero además como consecuencia de un modelo del hueco de la televisión de pago en España que fue decayendo tristemente desde su creación hasta la crisis actual y el cambio de accionariado. 


\section{Referencias bibliográficas}

ÁLVAREZ MONZONCILLO, José María; MENOR, Juan (2010). La televisión, entre la gratuidad y el pago. En: Telos, $\mathrm{n}^{\circ} 85$, pp. 1-9.

CASCAJOSA, Concepción (2005). Prime Time. Las mejores series de televisión americanas. De CSI a Los Soprano. Madrid: Calamar.

CASCAJOSA, Concepción (2006). No es televisión, es HBO. La búsqueda de la diferencia como indicador de calidad en los dramas del canal HBO. En ZER, vol. $11, \mathrm{n}^{\mathrm{o}} 21, \mathrm{pp} .23-33$.

CASCAJOSA, Concepción (2007). La caja lista. Televisión norteamericana de culto. Barcelona: Laertes.

CARRASCO, Ángel (2010). Teleseries: guiones y formatos. Ensayo de definiciones. En Miguel Hernández Communication Journal. n 1, pp. 174-200.

CAFFAREL, Carmen_(2005). ¿Es posible una televisión de calidad? En Comunicar. vol. XII, n ${ }^{\circ} 25$, pp. 23-27.

CAFFAREL, Carmen (2013). The reform of RTVE: Independence, plurality and new regulation (2004-2012). En NAJI, Jamal Eddine; THÉÔRET, Yves. (eds.). Reflexions sur les diversites mondiale. Marruecos: UNESCO-Cahiers de la HACA, pp. 287-297.

CANOVACA, Enrique (2011). La influencia del serial estadounidense en el mercado español: una comparativa entre Perdidos y El Internado. En: PÉREZ GÓMEZ, Miguel Angel (ed). Previously on. Estudios interdisciplinares sobre la ficción televisiva en la Tercera Edad de Oro de la televisión. Sevilla: Biblioteca de la Universidad de Sevilla, pp. 859-873.

DENZIN, Norman (1989). The Research Act: A Theoretical Introduction to Sociological Methods, New Jersey: Prentice Hall.

DIEGO, Patricia (2010). La ficción en la pequeña pantalla. Cincuenta años de series en España. Pamplona: Eunsa.

DIEGO, Patricia; GRANDÍO, María del Mar (2011). Clasicismo e innovación en la producción nacional de comedia televisiva en España (2000-2010). En Comunicación, Vol. 1, no 9, pp. 49-66.

DIEGO, Patricia; ETAYO, Cristina; PARDO, Alejandro (2011). La percepción sobre la calidad de las series televisivas en España: Contraste entre el público y los profesionales. En ZER. Vol. 16, n 31, pp. 69-88.

GECA (2013). El perfil de las series españolas de prime time. Geca-Globomedia, Madrid.

GRANDÍO, María Mar; DIEGO. Patricia (2009). La influencia de la sitcom americana en la producción de las comedias televisivas en España. En Ámbitos. Vol. 18 , pp. 83-97

GARCIAA DE CASTRO, Mario (2002). La ficción televisiva popular. Una evolución de las series televisivas en España. Barcelona: Gedisa.

GARCÍA DE CASTRO, Mario (2012). Crónica de las series de ficción españolas. En El Guion para series de Televisión. Madrid: IORTVE. pp. 25-44.

GARCÍA DE CASTRO, Mario (2015). La regresión cultural por parte de las series televisivas españolas. En PUEBLA, Belén; NAVARRO, Nuria; CARRILLO, Elena (coord.) Ficcionando en el Siglo XXI. Madrid: Estudios de Narrativa. Icono 14 Editorial. 
GARCÍA MARTÍNEZ, Alberto N. (2012). Una máquina de contar historias. Complejidad y revolución del relato televisivo. En La televisión en España: informe 2012, Barcelona: UTECA, pp. 225-246.

GUTIÉRREZ GEA, Charo (2000). Televisión y calidad: perspectivas de investigación y criterios de evaluación, en ZER, vol. 5, nº 9, pp.151-184.

INNOCENTI, Verónica; PESCATORE, Gugielmo (2011). Los modelos narrativos de la serialidad televisiva. En La Balsa de la medusa, no ${ }^{\circ}$, pp.31-50

MARTIN, Brett (2014). Hombres Fuera de Serie, Barcelona: Ariel.

MEDINA, Mercedes; OJER, Teresa (2011). La transformación de las televisiones públicas en servicios digitales en la BBC y RTVE. Comunicar, vol. XVIII, $\mathrm{n}^{\circ} 36$, pp. 87-94.

MORLEY, David (1996). Televisión, Audiencias y Estudios Culturales, Buenos Aires: Amorrortu.

PEREZ GOMEZ, M.A. (2011). Previously on: estudios interdisciplinarios sobre la ficción televisiva en la Tercera Edad de Oro de la Televisión. Sevilla: Biblioteca de la Facultad de Comunicación de la Universidad de Sevilla.

ROS, Enric. (2011). It's not tv. Las series de ficción en la era de la Pos-TV. Fundación Taller de Guionistas. Ministerio de Cultura.

SILVERSTONE, Roger. (1996). Televisión y Vida Cotidiana. Buenos Aires: Amorrortu.

THOMPSON, Robert J. (1996). Television's second Golden age. New York: Continuum.

TOUS, Anna. (2015) La política en las series de televisión. Barcelona: UOC. 



\title{
La comunicación visual de los productos a través del packaging. Un estudio de caso sobre la identidad visual de las botellas de leche
}

\author{
Produktuen komunikazio bisuala packaging-aren \\ bitartez. Esne-botilen identitate bisualari \\ buruzko kasu-azterketa
}

\section{Visual communication of products through packaging. A case study on the visual identity of milk bottles}

\author{
Jordi Colet Ruz ${ }^{1}$
}

\section{zer}

Vol. 21 - Núm. 40

ISSN: $1137-1102$

e-ISSN: $1989-631 X$

DOI: $10.1387 /$ zer. 15513

pp. $195-217$

2016

Recibido el 20 de enero de 2016, aceptado el 11 de abril de 2016.

\section{Resumen}

Los envases se han convertido en una pieza significativa del ecosistema visual que tiene un gran potencial comunicativo. Este potencial debe incluir la capacidad de transmitir la identidad tipológica del producto en un escenario muy competitivo. Esta investigación aborda la influencia del packaging en la identificación tipológica de los productos de alta frecuencia de compra. El objeto de estudio se ha focalizado en el código visual que regula el diseño de los envases, con el objeto de facilitar el reconocimiento tipológico del producto. Aquí se presenta un estudio de caso sobre el código visual en las botellas de leche.

Palabras-clave: Comunicación, diseño, marketing, percepción, publicidad.

\section{Laburpena}

Ontziak ekosistema bisualaren pieza esanguratsua bihurtu dira, eta komunikatzeko ahalmen handia dute. Ahalmen horrek produktuaren identitate tipologikoa transmititzeko gaitasuna izan behar du kontuan, agertokia oso lehiakorra baita. Ikerketa honek packaging-ak maiz erosten diren produktuen identifikazio tipologikoan duen eragina jorratzen du. Azterketak ontzien diseinua arautzen duen kode bisuala du ardatz, produktuaren azterketa tipologikoa errazteko helburuarekin. Hemen, esne-botilen kode bisualari buruzko kasu-azterketa bat aurkezten da.

Gako-hitzak: Komunikazioa, diseinua, marketina, pertzepzioa, publizitatea. 


\begin{abstract}
Packaging has become a significant part of the visual ecosystem which has a great potential for communication. This potential should include the ability to transmit the typological identity of product in a highly competitive scenario. This research approaches the influence of packaging on the typological identification of fast-moving consumer goods. The object of study has focused on the visual code that regulates packaging in order to facilitate the typological product recognition. This paper presents a case study on the visual code of milk bottles.
\end{abstract}

Key-words: Communication, design, marketing, perception, advertising. 


\section{Introducción}

La función de los envases se basa en la ineludible necesidad de contener, conservar y transportar productos. Sin embargo, dichos artefactos han experimentado una profunda transformación que los ha convertido en un instrumento al servicio del marketing. A través del packaging se logra articular la acción publicitaria de los productos en el punto de venta. La influencia comunicativa de los envases sobre el comportamiento de compra es significativa y su diseño gráfico puede representar una metáfora visual de nuestra sociedad contemporánea.

La construcción de la identidad visual de los productos tiene el difícil reto de facilitar la identificación inmediata del producto y, al mismo tiempo, transmitir los valores que conforman el posicionamiento publicitario de la marca. En este sentido, el diseño de los envases es la manifestación más elocuente de este reto.

La presente investigación expone los resultados de un proyecto experimental implementado para contrastar las hipótesis de trabajo expuestas por el autor en el marco de una tesis doctoral que aborda el estudio de la identidad visual de los envases desde la perspectiva del mensaje gráfico publicitario. En este sentido, el trabajo pretende ser una aportación al conocimiento de la denominada alfabetidad visual la cual, de acuerdo con Dondis (2004: 208), "significa una mayor inteligencia visual".

En definitiva, conocer la sintaxis visual en relación al diseño estructural y gráfico de los envases ha sido el principal propósito del trabajo; particularmente, la que afecta a los envases concebidos para los productos de alta frecuencia de compra (fast-moving consumer goods). Desde esta perspectiva, el resultado deberá permitir la formulación de mensajes más eficientes y, en consecuencia, mejorar el rendimiento comunicativo de los envases.

\section{Estado de la cuestión}

El vínculo entre la inteligencia humana y la realidad física -de carácter extracognitivo- se establece a través de la facultad perceptiva multisensorial de los seres humanos. Por esta razón, la recepción sensorial se erige como una causa fundamental que incide en la formación de la inteligencia humana. Todas las cosas que vemos, escuchamos, olemos, degustamos y tocamos delimitan nuestros aprendizajes, experiencias, sensaciones y pensamientos; son los estímulos a partir de los cuales se construye la propia inteligencia y una determinada -y necesariamente limitada- concepción del mundo exterior.

Inmersos en un entorno comercial afectado por una alta saturación de estímulos sensoriales, la identidad visual de los envases deviene un factor relevante en este ecosistema que incorpora un gran potencial comunicativo. De hecho, el punto de venta los ha transformado en unos auténticos artefactos publicitarios de gran importancia estratégica para las marcas. El desarrollo de este potencial queda sintetizado por la capacidad de transmitir la identidad tipológica del producto y de la marca en un momento decisivo: el acto de compra.

El problema de conocimiento que plantea esta investigación versa sobre cómo la identidad visual de los envases permite la identificación tipológica del producto y, al mismo tiempo, de qué manera este hecho puede provocar una afectación sobre la 
preferencia del receptor. Es decir, el objetivo es conocer cómo se formula el mensaje visual a fin de potenciar la comunicación publicitaria del envase en el punto de venta.

En base a lo expuesto, el objeto de estudio se ha centrado en la existencia de un código visual y en los efectos positivos que se derivan de su aplicación sobre el comportamiento de los sujetos. En otras palabras, la finalidad de la investigación es contrastar si la identidad visual de los envases se encuentra regida, en mayor o menor medida, por un código visual. Por este motivo, la observación del receptor, expuesto a una determinada formulación visual, es un requerimiento básico para el estudio de su comportamiento de compra. Como apunta Rom (2002: 152), "la posibilidad de establecer códigos visuales para facilitar el acto de comunicación y aumentar la eficacia de los mensajes hace necesario el estudio del imaginario iconográfico de los públicos del diseño". Precisamente, esto es lo que aquí se ha estudiado de forma experimental; cómo se establecen premeditadamente unas formulaciones visuales en torno a un caso particular: las botellas de leche. En definitiva, el trabajo pretende concretar si determinados prototipos visuales son portadores de un código tipológico que determina la identidad estructural y gráfica de los envases de leche.

Desde una perspectiva científica, abordar el estudio del packaging supone un reto para el avance del conocimiento en diseño gráfico, para convertir los envases en artefactos más eficaces y eficientes a nivel comunicativo. En palabras de Bunge (1989: 45), "la investigación científica es, dicho brevemente, la búsqueda de estructuras". Es decir, la ciencia se fundamenta en la búsqueda de categorías e interrelaciones para comprender y transformar -cuando esto sea posible- el funcionamiento de las cosas.

La teoría general de los sistemas formulada por Ludwing von Bertalanffy (1981: $45)$ se sustenta en esta idea inicial. Bertalanffy proporcionó un nuevo enfoque a la investigación científica sobre la base que todo objeto de estudio forma parte de una realidad más global. Una realidad determinada por los hechos y explicada a partir de la investigación sobre los componentes que la integran y las relaciones que se establecen. Desde este punto de vista, no es casual que este autor justifique "la aparición, en todos los campos de la ciencia, de nociones como las de totalidad, holismo, organismo, Gestalt, etc., que vienen a significar todas que, en última instancia, debemos pensar en términos de sistemas de elementos en interacción mutua."

Los primeros paradigmas comunicativos se inspiran en este principio sistémico. La investigación de la comunicación humana como disciplina científica arranca a mediados del siglo XX cuando se presentan los modelos comunicativos de Harold D. Lasswell y Claude E. Shannon, entre otros (Saperas, 1985). Estos primeros modelos se originan en el marco de la Mass Communication Research con la finalidad de explicar los principios que regulan la comunicación y, al mismo tiempo, establecer unas incipientes bases teóricas sobre el tema. De hecho, el interés de la investigación científica en este ámbito se centraba en analizar, fundamentalmente, los efectos de los medios de comunicación de masas; es decir, la capacidad de influencia de los medios en la opinión pública.

Estos primeros modelos comunicativos han quedado como referentes históricos. En la actualidad, la comunicación en general -y muy especialmente, la publicitaria- ha experimentado numerosos cambios para adaptarse a las nuevas necesidades y exigencias de una sociedad moderna, más compleja y diversa, sobresaturada de estímulos, en la cual la creatividad tiene que hacer un gran esfuerzo de conceptualización de los mensajes. 
Una de estas formas de expresión publicitaria se ha manifestado a través del packaging. Las actuales exigencias y hábitos de consumo -los nuevos formatos de producto, la usabilidad de los envases o el impacto medioambiental que generan, entre otros- han incentivado su crecimiento económico y, también, su desarrollo técnico y comunicativo. En este contexto, la función publicitaria del envase ha sido decisiva. Los envases han devenido algo más que unos artefactos donde contener, conservar y transportar unos determinados productos; son, sobretodo, la expresión visual de un mensaje. Desde este punto de vista, se erigen como una auténtica y valiosa herramienta de marketing en un mercado de consumo donde las características, la calidad y el precio de los productos pueden resultar muy similares (Veryzer, 1995). En suma, los envases permiten comunicar y generar identidad de marca, especialmente en un mercado de fuerte competencia (Connolly, 1996; Rettie, 2000). Como bien dice Bassat (1994: 35), no podemos olvidar la función publicitaria del envase dado que "es el último interlocutor de nuestro cliente, en él delegamos el cierre de la venta, y para ello debemos dotarlo de toda la información, de toda la capacidad de persuasión y de toda la personalidad diferencial que sea posible". Ante productos similares en calidad y precio, la comunicación publicitaria a través del envase es crucial. Por este motivo, el packaging es un factor determinante que afecta el comportamiento de compra (Veryzer, 1995).

En el marco de esta concepción sistémica del proceso comunicativo, una primera reflexión en torno al packaging permite plantear una modelización de dicho proceso. A pesar de que, en palabras de Arnheim (2005: 73), "los constructos teóricos nunca pretenden otra cosa que dar una versión aproximada de las complejidades de la realidad", se trata de un punto de partida útil y necesario. Su finalidad es ofrecer una perspectiva general del proceso para situar adecuadamente el objeto de estudio y, a la vez, representar gráficamente su carácter sistémico.

La referida propuesta de modelización (Figura 1) contempla cuatro grandes dimensiones interdependientes las cuales corresponden a las etapas de concepción, producción, difusión y recepción del mensaje. No obstante, en esta investigación sólo se desarrolla la dimensión comunicativa del pack desde la perspectiva del mensaje gráfico publicitario.

En términos generales, el origen de la actividad comunicativa parte de un emisor; de una persona física o jurídica que tiene la necesidad o el propósito de transmitir un mensaje. Naturalmente, cuando la comunicación tiene carácter comercial, el objetivo es persuadir para provocar un determinado comportamiento de compra.

Dicha modelización considera la dimensión comunicativa como aquella parte del proceso centrada fundamentalmente en la construcción formal del mensaje. Por tanto, su importancia estratégica reside, por un lado, en aquello que se quiere decir sobre el producto pero, por el otro, en cómo se pretende abordar a través del diseño estructural y gráfico de los envases.

De acuerdo con lo dicho, el desencadenante del proceso comunicativo tiene relación con una fuente de información representada por el anunciante o el cliente. Esta fuente de información es la responsable de planificar una determinada estrategia de marketing y, también, de elaborar un briefing a partir del cual el emisor -léase diseñador o codificador- dispondrá de los requerimientos básicos para formular y defender las propuestas de mensaje visual. Sea una agencia de publicidad o estudio 
de comunicación, el emisor siempre parte de un conjunto de datos sin los cuales el proyecto va a resultar inviable e infructuoso.

Cuando el anunciante decide la promoción de un producto, la agencia de publicidad y el equipo de diseño se erigen como el emisor en tanto que reciben el encargo de concebir el mensaje a partir de unos objetivos. Conceptualmente, el emisor tiene la responsabilidad de definir la identidad visual del envase, desde la estrategia comunicativa hasta la concepción estructural y gráfica del artefacto. En este mismo sentido se posiciona Dondis $(2004,33)$ cuando para referirse al proceso de composición visual dice que "en esta etapa vital del proceso creativo, es donde el comunicador visual ejerce el control más fuerte sobre su trabajo y donde tiene la mayor oportunidad para expresar el estado de ánimo total que se quiere transmita la obra". De hecho, la función primordial de este equipo de trabajo multidisciplinar -en el cual los creativos marcan una estrategia comunicativa y los diseñadores plantean probables formulaciones visuales- es la definición conceptual y formal del mensaje (Figura 2).

Figura 1: Modelización del proceso de comunicación publicitaria a través de los envases.

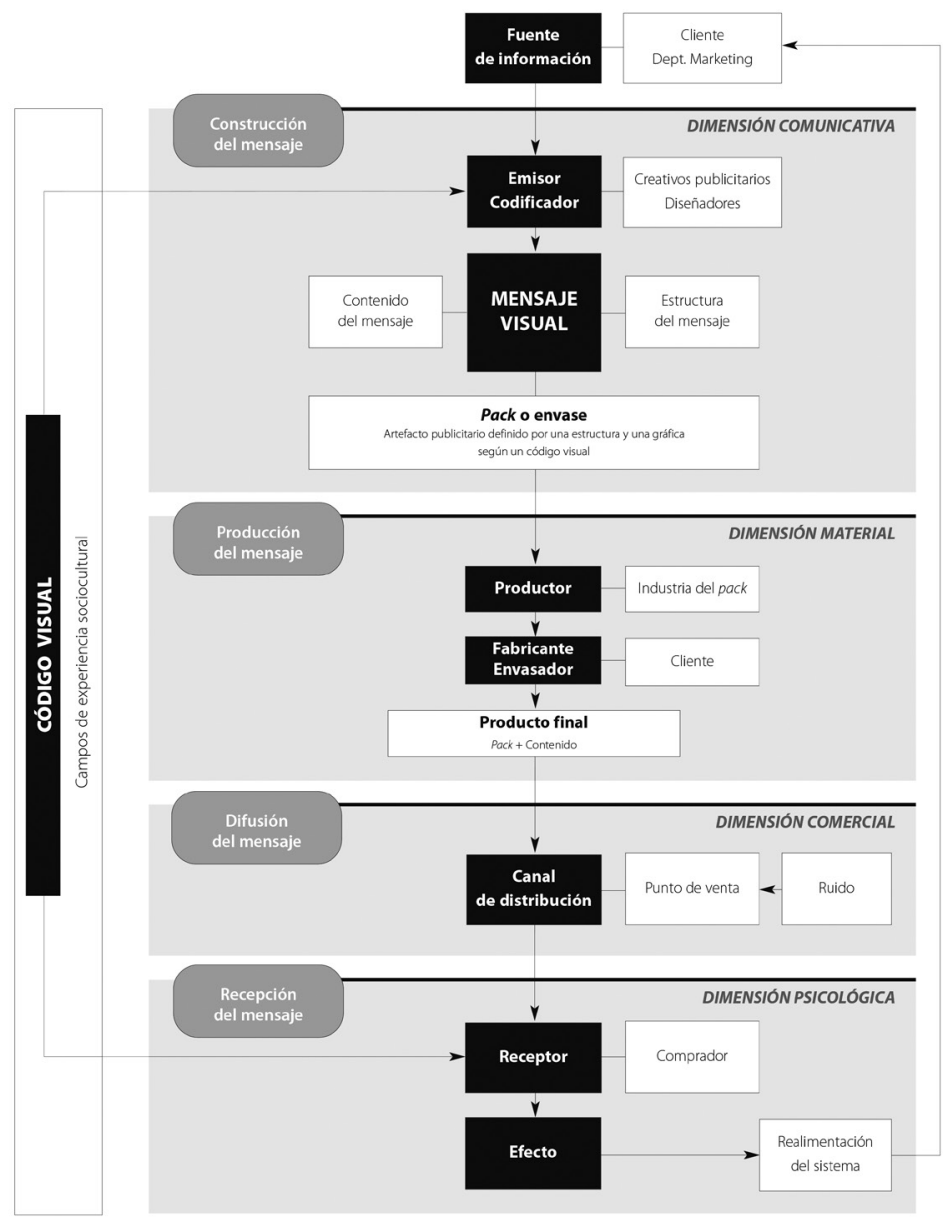

Fuente: Elaboración propia. 
Figura 2: Proceso de construcción formal del mensaje publicitario en los envases.

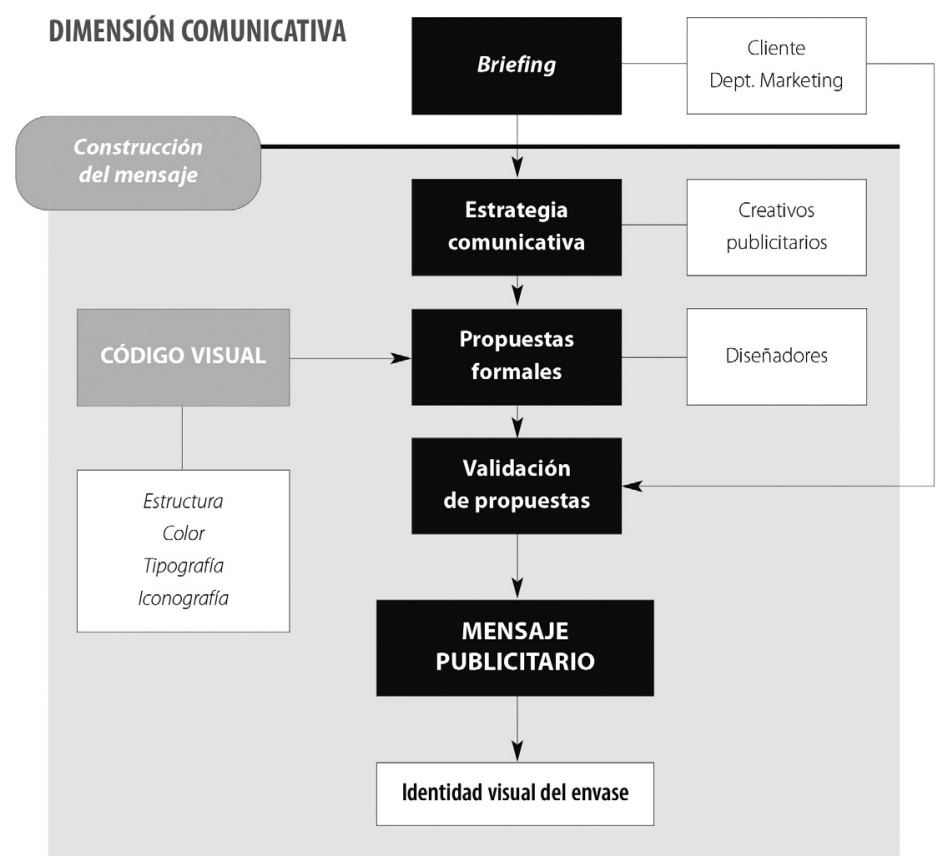

Fuente: Elaboración propia.

Atendiendo a su dimensión comunicativa, el envase no puede ser considerado un simple contenedor. Su diseño estructural y gráfico permite la representación de la propia identidad visual de los productos. De hecho, transforma el envase en portador de un mensaje publicitario que debe persuadir al comprador. Como afirma Vidales (2003: 21), "el envase es considerado como un objeto-mensaje que participa de un proceso de comunicación". Aunque el aspecto exterior del pack no sea considerado stricto sensu el producto, las propiedades estructurales y gráficas del artefactocontenedor devienen una parte indisociable del mismo. Desde esta perspectiva, los envases también se conciben como objeto de consumo dado que participan activamente del proceso de compra, particularmente en algunas tipologías de producto. En muchos casos, las propiedades funcionales, nutritivas o terapéuticas del contenido son sólo una condición necesaria aunque no suficiente para lograr la preferencia del consumidor. Según Viñolas (2005: 323), “en la actualidad y salvo raras excepciones, la esencia de los envases no son los productos sino la imagen, las asociaciones y metaprestaciones, de modo que éstas se han convertido en el soporte de las marcas y en símbolo de su prestigio". Por esta razón, los envases sobrepasan las propiedades del contenido y devienen parte significativa del producto que se pretende vender.

Desde un planteamiento semiótico, este conjunto de propiedades estructurales y gráficas de los envases son signos visuales, elementos de significación, creados y organizados según una determinada convención cultural. Como expone Eco (1972), se dan códigos arquitectónicos que indican qué forma tienen las construcciones -o los 
objetos que forman parte de nuestro entorno- a través de las cuales se puede reconocer la identidad de las mismas. En este sentido, Vidales $(2003,21)$ afirma que "como objetos semióticos, los envases y embalajes son soportes de información, vehículos de mensajes, portadores de significados".

Asimismo, el lenguaje visual de los productos es un hecho social y cultural; un patrimonio colectivo determinado -según la sociología de la comunicación- por los campos de experiencia. De acuerdo con Saperas $(1985,83)$ dicho concepto se utiliza para definir "el conjunto de conocimientos de naturaleza cultural o aprehendidos a lo largo de la actividad cotidiana que permiten a cada individuo determinar su conducta en cada ocasión según sus propios conocimientos". Otros autores como DeFleur (1982) se refieren a las construcciones socioculturales de la realidad. En este sentido, la presencia de un código visual en el packaging es una expresión particular de la cultura visual de nuestra sociedad; una parte de la memoria colectiva que surge como consecuencia de unos espacios de relación comercial, social y cultural.

La apariencia de los envases, su aspecto visual, es un factor importante que influye al comprador durante el proceso de selección de un producto en el punto de venta (Bloch, 1995; Garber, 1995; Veryzer, 1995; Sierra, 2001; Martínez Bouza, 2010); en particular, si se considera que más de la mitad de las decisiones de compra se adoptan habitualmente en el mismo punto de venta o bien no estaban previamente planificadas (Philips, 1993; Connolly, 1996).

Para abordar la cuestión sobre la identidad visual de los envases se ha adoptado el concepto de Estado Estético propuesto por Max Bense y recuperado por Daniel Tena (1998). En este sentido, cualquier artefacto es portador de un determinado Estado Estético que se origina mediante el concurso de diversos elementos visuales $y$ gráficos, y con la finalidad de suscitar la preferencia del receptor. Desde la perspectiva del packaging, el Estado Estético trata sobre una formulación visual que configura la identidad de los productos y que, para ser debidamente investigada, debe ser observada a través de la percepción humana. En este caso particular, se pretende su aplicación al estudio de la identidad de los productos de alta frecuencia de compra (fast-moving consumer goods).

Una aproximación a la dimensión comunicativa de estos artefactos permite plantear que la construcción de esta identidad visual pueda estar regulada -en mayor o menor medida- por el concurso de un código específico. Un código instituido a partir de las propiedades estructurales y gráficas del artefacto visual gracias a las cuales se puede identificar el carácter tipológico de los productos y las marcas. ${ }^{2}$ En este caso, la configuración del Estado Estético se articularía por la acción de dicho código.

Considerando que el proceso de selección de un producto tiende-especialmente cuando se trata de actividades rutinarias- hacia la eficiencia de los recursos cognitivos, la presencia de un código tipológico en los envases puede ser un mecanismo útil para agilizar el reconocimiento del producto en el punto de venta. En este sentido, un deficiente uso del código puede inducir a la desorientación o confusión del receptor. Como afirma Eco (1977: 418), "desde el punto de vista semiótico, la ambiguiedad puede definirse como violación de las reglas del código".

\footnotetext{
La Ley de marcas (BOE n ${ }^{\circ} 294,8$ de diciembre de 2001) entiende que las formas tridimensionales, entre las que se incluyen las formas de los envases y los embalajes, pueden considerarse marcas siempre que se atiendan las condiciones que establece la ley.
} 
En relación a la importancia del aspecto visual del producto con respecto a la preferencia del consumidor, Creusen (2005) contempla que una acusada diferencia o similitud con los productos de la misma categoria puede ser una estrategia beneficiosa según la situación. Por esta razón, la baja implicación de los sujetos en procesos de compra asiduos favorece que los productos con un aspecto visual tipificado tengan una mayor aceptación social debido al menor esfuerzo mental requerido (Hoyer, 1984). En estas circunstancias, tipificar el aspecto visual del producto es recomendable (Alba, 1987). En contraposición, cuando el posicionamiento de un producto se fundamenta en el prestigio, la exclusividad o la novedad, es aconsejable que su aspecto se destaque significativamente del resto (Ward, 1988).

Los procesos de aprendizaje, reconocimiento e interpretación de los estímulos sensoriales son la base a partir de la cual el receptor puede articular una determinada respuesta. Pero la percepción no se explica exclusivamente por la presencia de unas sensaciones de naturaleza física canalizadas a través de los sentidos; no es un proceso pasivo de entrada de estímulos sino una actividad centrada en la selección, organización y actualización de los datos que aportan los sentidos (Viglietti, 1975). La sensación tiene carácter reactivo; es simplemente una reacción que se origina por la acción de un estímulo sobre un receptor sensorial que envía un impulso nervioso al cerebro (Schnake, 1990).

Por otra parte, el acto de la percepción es más profundo y complejo. Es un proceso cognitivo que conlleva un filtrado e interpretación de la información. La percepción transforma las sensaciones físicas vehiculadas por los sentidos en significados; es un proceso de semiosis (Costa, 2004).

Las investigaciones realizadas por la Escuela Gestalt sobre la percepción humana han sido un modelo de referencia para la comunicación visual. Los trabajos de esta escuela concluyeron, por un lado, que "el estímulo se percibe como un todo" y, por el otro, que "el individuo posee un mecanismo cognitivo hacia una configuración cognitiva ordenada" (Aaker, 1984: 64). El primero corresponde al principio de la totalidad; la percepción es concebida como una actividad basada en la síntesis de estímulos. El proceso perceptivo se origina a partir de un conjunto de elementos visuales que integran una totalidad, una configuración identificable o gestalt en la cual la percepción de la globalidad es más importante que la de los componentes por separado. El segundo principio defiende que el sistema cognitivo dispone de mecanismos que facilitan la percepción a través de pautas visuales. La ley gestáltica de pregnancia plantea que cuando las sensaciones se organizan para construir formas, el sistema cognitivo las percibe siguiendo el criterio de la simplicidad. La manera más sencilla de alcanzar la simplicidad de un artefacto visual es a través de la reducción y organización de los elementos que lo conforman. Según afirma Maeda (2006: 89), la simplicidad es "sustraer lo que es obvio y añadir lo específico".

Desde el ámbito de la psicología cognitiva también se han realizado aportaciones conceptuales que permiten entender la profundidad del fenómeno perceptivo. Una de las condiciones que intervienen en el funcionamiento del sistema cognitivo es la formación de estructuras mentales; es decir, la organización de la información en categorías para poder clasificar y relacionar el conocimiento en función de determinados criterios taxonómicos (Sierra, 2001). 
La categorización es un concepto que pone de manifiesto la tendencia humana hacia la organización y significación de la experiencia sensorial; una función básica de carácter cognitivo que guía el comportamiento humano. En este sentido, DeFleur (1982: 180) afirma que la percepción es "la actividad mental por la cual el ingreso de datos sensoriales es clasificado dentro de categorías reconocibles de experiencias".

De acuerdo con esto, la creación de categorías por parte del sistema cognitivo obedece a la necesidad de organización del conocimiento para gestionarlo de forma eficaz y eficiente; es decir, permite la identificación tipológica de los productos y las marcas en el punto de venta. Sierra (2001) plantea la función de la apariencia visual de los envase en el proceso de categorización, especialmente cuando el comprador necesita diferenciar los productos, marcas y variedades.

Otros autores como Garber (1995), Bloch (1995) y Veryzer (1995) han destacado la influencia del diseño en la categorización dado que una de las principales funciones de las categorías es diferenciar los productos durante el proceso de compra. En particular, Garber (1995) defiende que el diseño de los envases determina el reconocimiento de los productos a partir de una apariencia visual más o menos prototípica.

Schoormans (1997) recomienda que los envases deberían establecer diferencias evidentes entre los productos, aunque también reconocen que los efectos positivos de la apariencia prototípica pueden desaparecer si no se respetan los códigos visuales establecidos para una determinada categoría. Por otra parte, las aportaciones de Bloch (1995) y Veryzer (1995) sobre esta cuestión indican que la creación de prototipos visuales facilita la categorización de los productos; en concreto, destacan la importancia de la estructura del envase.

Desde la perspectiva del sistema cognitivo, la percepción de disonancia originada por la transgresión de un código tiene importantes implicaciones en el diseño de los envases. Según la teoría de la disonancia cognitiva de Festinger (1975), el comportamiento de los sujetos se rige por el equilibrio entre cognición y acción. Dicha dualidad encuentra el equilibrio necesario cuando entre el pensamiento y el comportamiento se ha establecido una relación de coherencia.

La manifestación de un hecho disonante es algo que produce incomodidad en los sujetos dado que es el resultado de una respuesta no consecuente con lo que se piensa o sabe. "Cuando un consumidor recibe información acerca de cierto producto que no concuerda con lo que él siente hacia el producto, experimenta una incomodidad intelectual o inconsistencia que se denomina disonancia cognitiva" (Schnake, 1990 : 90). Por esta razón, esta incomodidad conlleva habitualmente la justificación del propio comportamiento.

El fenómeno de la disonancia cognitiva aplicado al diseño de los envases ha sido abordado por Julia von Fraunberg ${ }^{3}$. Esta diseñadora ha investigado sobre los efectos del intercambio de identidades gráficas en los envases de algunos productos; en concreto, aquellas que son visualmente más prototípicas para una determinada tipología de producto. Fraunberg plantea una situación de disonancia cognitiva originada por la percepción de la identidad visual de los envases. Un escenario en el cual los sujetos se sienten desconcertados dado que las propiedades estructurales y gráficas del contenedor no se ajustan al contenido real envasado. De hecho, dicha disonan-

3 Su trabajo se encuentra publicado en: CAPELLA, Juli y ÚBEDA, Ramon. Cocos, copias y coincidencias. Barcelona: Editorial Electa, 2003. 
cia está originada por una transgresión del código visual. En suma, el propósito de su investigación era constatar que el proceso de elección de productos envasados -especialmente, cuando son de alta frecuencia de compra- queda condicionado por unos códigos visuales preestablecidos.

\section{Metodología}

En la presente investigación se ha adoptado una metodología experimental. Cada variable se refiere a una propiedad intrínseca del artefacto visual. En concreto, la estructura del envase y dos valores cromáticos específicos han sido las variables independientes a partir de las cuales se determinaron los tratamientos experimentales.

La primera variable del experimento (estructura) corresponde a la forma tridimensional del contenedor; la segunda (color_base) determina el principal valor cromático de su superficie; finalmente, la tercera variable (color_auxiliar) se asocia con otro valor cromático significativo, pero de menor impacto visual.

La estrategia utilizada en esta investigación ha sido un diseño factorial de medidas repetidas (within-subject design). Con este procedimiento estadístico se ha planteado la manipulación simultánea de las tres variables independientes y, consiguientemente, se han podido analizar dos cuestiones de interés: la influencia que cada variable tiene sobre la variable dependiente y, al mismo tiempo, los efectos de la interacción detectados entre las propias variables independientes. Por tanto, se procede a la valoración de los efectos que cada factor provoca en la variable de estudio pero considerando, también, la situación puntual del resto de los factores manipulados en el experimento.

En particular se trata de un diseño (3) x (3) x (3). Es decir, un único grupo se somete a un conjunto de 27 tratamientos experimentales. La primera variable -estructura-tiene 3 niveles; la segunda -color base-dispone de 3 niveles más y, finalmente, la última variable -color auxiliar - también presenta 3 niveles. La exposición del grupo a la totalidad de los tratamientos ha permitido la recogida de los datos necesarios para su posterior análisis estadístico.

El principal propósito de este experimento es contrastar la existencia de un código visual en los envases de leche. En concreto, se quiere saber si la identidad visual de las botellas de leche entera ha quedado establecida por unas especificaciones estructurales y cromáticas determinadas. A continuación se exponen las hipótesis de trabajo que se pretenden validar.

$\mathrm{H}_{1}$ La forma estructural del envase es un componente del código visual.

$\mathrm{H}_{2}$ El valor cromático base del envase es un componente del código visual.

$\mathrm{H}_{3}$ El valor cromático auxiliar del envase es un componente del código visual.

$\mathrm{H}_{4}$ Cuando se combina en un envase el valor cromático base con el valor cromático auxiliar se identifica la tipología del producto.

$\mathrm{H}_{5}$ Cuando se combina la estructura del envase con los valores cromáticos base y auxiliar se identifica la tipología del producto.

Para la realización del experimento se ha utilizado una audiencia cautiva. Es decir, los participantes han formado parte de una muestra de conveniencia integrada por 
un grupo de 45 estudiantes universitarios de la Facultad de Ciencias de la Comunicación de la Universidad Autónoma de Barcelona (UAB) que estaban cursando estudios de Periodismo. En este sentido -y de acuerdo con los planteamientos metodológicos formulados por Igartua (2006) - el uso de las muestras de conveniencia constituidas por estudiantes universitarios es un hecho aceptado y habitual cuando se hacen investigaciones científicas en Comunicación. Un 26\% de la muestra estaba formada por hombres y un $74 \%$ por mujeres, entre 18 y 25 años.

El desarrollo de la prueba experimental se realizó a través de la Plataforma para el Análisis de la Recepción en Comunicación (denominada PARC ${ }^{4}$ ). Se trata de un instrumento al servicio de los investigadores concebido para la preparación, administración y control de los ensayos científicos que se basan en la percepción visual. Esta aplicación ha permitido el montaje del test de recepción el cual presenta, por un lado, una proposición de respuesta cerrada (escala tipo Likert de cinco niveles de respuesta) y, por el otro, unos estímulos visuales premeditadamente manipulados y controlados por el investigador. En esta ocasión, dicho enunciado afirmaba textualmente lo siguiente:

"Esta maqueta corresponde a una botella de leche entera"

\section{Análisis estadístico}

En el contexto de la estadística inferencial, se procede a efectuar una valoración preliminar sobre el funcionamiento del instrumento de medida implementado en este experimento. En este sentido, la medida de la fiabilidad del instrumento se convierte en un indicador básico de análisis que tiene el objetivo de garantizar la calidad de los datos obtenidos. De acuerdo con esto, se ha controlado la capacidad métrica del cuestionario con la aplicación informática SPSS Statistics y a través del coeficiente Alfa de Cronbach.

Según los resultados obtenidos, se comprueba que la fiabilidad del instrumento es muy buena $(0,875)$ dado que el valor obtenido se encuentra entre 0,70 y 0,90 . Por tanto, se puede asegurar que los ítems de la escala miden efectivamente el mismo atributo.

Se ha adoptado un diseño factorial de la varianza con medidas repetidas para poder valorar, por una parte, los efectos principales de las variables independientes sobre la variable dependiente $\mathrm{y}$, por otra, los posibles efectos de interacción entre las variables objeto de estudio. En este sentido, el análisis de los efectos es la base a partir de la cual se podrá contrastar en qué medida las hipótesis formuladas son válidas.

En el análisis estadístico se ha considerado el nivel de significación y la potencia del contraste como criterios básicos de decisión. Asimismo, el procedimiento utilizado para analizar los datos obtenidos ha sido el GLM (General Linear Model).

\subsection{Primera hipótesis}

$\mathrm{H}_{1}$ La forma estructural del envase es un componente del código visual.

\footnotetext{
${ }^{4}$ La información técnica sobre la Plataforma para el Análisis de la Recepción en Comunicación (PARC) ha sido publicada en: LÁZARO, Patricia; TENA, Daniel; BLANCO, Josep Maria; VOCES, Ramon (2007). La recepción, un límite a la creación. Trípodos (número extraordinario), pp. 685-704.
} 
Dado que el nivel de significación (sig.) relativo al factor Estructura es 0,001 -por tanto, inferior a 0,05- se puede rechazar la hipótesis nula y, en consecuencia, concluir que se detectan diferencias significativas entre las estructuras de la botella (Tabla 1). Dicho en términos estadísticos, se dispone de suficientes garantías para no incurrir en un error Tipo I y, por tanto, se puede aceptar la credibilidad de dicha hipótesis.

Asimismo es importante considerar la excelente potencia estadística del contraste $(0,968)$ la cual, como puede comprobarse, es bastante superior a 0,80. Por tanto, la probabilidad de cometer un error Tipo II es muy baja.

Por otra parte, las medias marginales estimadas del factor Estructura (Tabla 2) relativas a las maquetas A, B y C (Figura 3) indican que la media más alta corresponde a la maqueta $B(2,291)$.

Tabla 1. Valores estadísticos de significación y potencia de los contrastes relativos al factor Estructura.

\begin{tabular}{|l|c|c|c|c|c|c|c|}
\hline \multicolumn{7}{|c|}{ ESTRUCTURA } \\
\hline $\begin{array}{l}\text { Contrastes } \\
\text { multivariados }\end{array}$ & Valor & F & $\begin{array}{c}\text { GI de la } \\
\text { hipótesis }\end{array}$ & $\begin{array}{c}\text { GI del } \\
\text { error }\end{array}$ & Sig. & $\begin{array}{c}\text { Coeficiente } \\
\mathbf{r}^{2}\end{array}$ & $\begin{array}{c}\text { Potencia } \\
\text { observada }\end{array}$ \\
\hline Traza de Pillai &, 316 & 9,244 & 2,000 & 40,000 &, 001 &, 316 &, 968 \\
\hline $\begin{array}{l}\text { Lambda } \\
\text { de Wilks }\end{array}$ &, 684 & 9,244 & 2,000 & 40,000 &, 001 &, 316 &, 968 \\
\hline $\begin{array}{l}\text { Traza } \\
\text { de Hotelling }\end{array}$ &, 462 & 9,244 & 2,000 & 40,000 &, 001 &, 316 &, 968 \\
\hline $\begin{array}{l}\text { Raíz mayor } \\
\text { de Roy }\end{array}$ &, 462 & 9,244 & 2,000 & 40,000 &, 001 &, 316 &, 968 \\
\hline
\end{tabular}

Tabla 2. Medias obtenidas por el factor Estructura en las maquetas A, B y C.

\begin{tabular}{|c|c|c|c|c|}
\hline \multicolumn{5}{|c|}{ MEDIAS MARGINALES ESTIMADAS } \\
\hline \multirow{2}{*}{$\begin{array}{c}\text { Estructura } \\
\text { de la maqueta }\end{array}$} & Media & \multirow{2}{*}{ Error típico } & \multicolumn{2}{|c|}{ Intervalo de confianza 95\% } \\
\cline { 4 - 5 } & & & Límite inferior & Límite superior \\
\hline A & 1,952 &, 083 & 1,785 & 2,120 \\
\hline B & 2,291 &, 103 & 2,083 & 2,499 \\
\hline C & 2,122 &, 094 & 1,931 & 2,312 \\
\hline
\end{tabular}


Figura 3. Representación gráfica de las respectivas maquetas A, B y C.

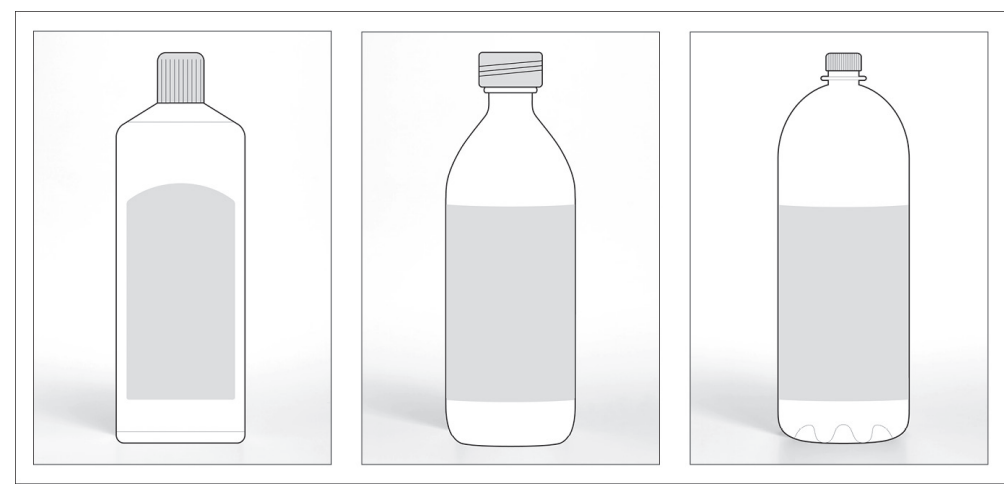

Fuente: Elaboración propia.

\subsection{Segunda hipótesis}

$\mathrm{H}_{2}$ El valor cromático base del envase es un componente del código visual.

Dado que el nivel de significación (sig.) relativo al factor Color_Base es 0,00 se puede rechazar la hipótesis nula y, en consecuencia, concluir que se detectan diferencias significativas entre los valores cromáticos base de las botellas (Tabla 3). Se puede aceptar la credibilidad de dicha hipótesis.

Asimismo es importante considerar la excelente potencia estadística del contraste $(1,00)$ la cual es superior a 0,80 .

Tabla 3. Valores estadísticos de significación y potencia de los contrastes relativos al factor Color_Base.

\begin{tabular}{|l|c|c|c|c|c|c|c|}
\hline \multicolumn{7}{|c|}{ COLOR_BASE } \\
\hline $\begin{array}{l}\text { Contrastes } \\
\text { multivariados }\end{array}$ & Valor & F & $\begin{array}{c}\text { GI de la } \\
\text { hipótesis }\end{array}$ & $\begin{array}{c}\text { GI del } \\
\text { error }\end{array}$ & Sig. & $\begin{array}{c}\text { Coeficiente } \\
\mathbf{r}^{2}\end{array}$ & $\begin{array}{c}\text { Potencia } \\
\text { observada }\end{array}$ \\
\hline Traza de Pillai &, 768 & 66,090 & 2,000 & 40,000 &, 000 &, 768 & 1,000 \\
\hline $\begin{array}{l}\text { Lambda } \\
\text { de Wilks }\end{array}$ &, 232 & 66,090 & 2,000 & 40,000 &, 000 &, 768 & 1,000 \\
\hline $\begin{array}{l}\text { Traza } \\
\text { de Hotelling }\end{array}$ & 3,304 & 66,090 & 2,000 & 40,000 &, 000 &, 768 & $\mathbf{1 , 0 0 0}$ \\
\hline $\begin{array}{l}\text { Raíz mayor } \\
\text { de Roy }\end{array}$ & 3,304 & 66,090 & 2,000 & 40,000 &, 000 &, 768 & $\mathbf{1 , 0 0 0}$ \\
\hline
\end{tabular}

Por otra parte, las medias marginales estimadas del factor Color_Base (Tabla 4) indican que la media más alta $(3,034)$ corresponde al valor cromático base 1 (muestra B1); en contraposición, los valores cromáticos base 2 (muestra B2) y 3 (muestra B3) han alcanzado unos resultados muy inferiores. 
Tabla 4. Medias marginales estimadas obtenidas por el factor Color_Base.

\begin{tabular}{|c|c|c|c|c|}
\hline \multicolumn{5}{|c|}{ MEDIAS MARGINALES ESTIMADAS } \\
\hline \multirow{2}{*}{ Color_Base } & Media & \multirow{2}{*}{ Error típico } & \multicolumn{2}{|c|}{ Intervalo de confianza 95\% } \\
\cline { 4 - 5 } & & & Límite inferior & Límite superior \\
\hline 1 & 3,034 &, 100 & 2,833 & 3,235 \\
\hline 2 & 1,608 &, 100 & 1,406 & 1,811 \\
\hline 3 & 1,722 &, 111 & 1,498 & 1,947 \\
\hline
\end{tabular}

\subsection{TERCERA HIPÓTESIS}

$\mathrm{H}_{3}$ El valor cromático auxiliar del envase es un componente del código visual.

Dado que el nivel de significación (sig.) relativo al factor Color_Auxiliar es 0,00 se puede rechazar la hipótesis nula y, en consecuencia, concluir que se detectan diferencias significativas entre los valores cromáticos auxiliares de los envases (Tabla 5). Se puede aceptar la credibilidad de dicha hipótesis.

Asimismo es importante considerar la excelente potencia estadística del contraste $(1,00)$ la cual es superior a 0,80 .

Tabla 5. Valores estadísticos de significación y potencia de los contrastes relativos al factor Color_Auxiliar.

\begin{tabular}{|l|c|c|c|c|c|c|c|}
\hline \multicolumn{7}{|c|}{ COLOR_AUXILIAR } \\
\hline $\begin{array}{l}\text { Contrastes } \\
\text { multivariados }\end{array}$ & Valor & F & $\begin{array}{c}\text { GI de la } \\
\text { hipótesis }\end{array}$ & $\begin{array}{c}\text { GI del } \\
\text { error }\end{array}$ & Sig. & $\begin{array}{c}\text { Coeficiente } \\
\mathbf{r}^{2}\end{array}$ & $\begin{array}{c}\text { Potencia } \\
\text { observada }\end{array}$ \\
\hline Traza de Pillai &, 551 & 24,544 & 2,000 & 40,000 &, 000 &, 551 & 1,000 \\
\hline $\begin{array}{l}\text { Lambda } \\
\text { de Wilks }\end{array}$ &, 449 & 24,544 & 2,000 & 40,000 &, 000 &, 551 & 1,000 \\
\hline $\begin{array}{l}\text { Traza } \\
\text { de Hotelling }\end{array}$ & 1,227 & 24,544 & 2,000 & 40,000 &, 000 &, 551 & 1,000 \\
\hline $\begin{array}{l}\text { Raíz mayor } \\
\text { de Roy }\end{array}$ & 1,227 & 24,544 & 2,000 & 40,000 &, 000 &, 551 & 1,000 \\
\hline
\end{tabular}

Por otra parte, las medias marginales estimadas del factor Color_Auxiliar (Tabla 6) indican que la media más alta $(2,688)$ corresponde al valor cromático auxiliar 1 (muestra A1); en contraposición, los valores cromáticos auxiliar 2 (muestra A2) y 3 (muestra A3) han alcanzado unos resultados muy inferiores. 
Tabla 6. Medias marginales estimadas obtenidas por el factor Color_Auxiliar.

\begin{tabular}{|c|c|c|c|c|}
\hline \multicolumn{5}{|c|}{ MEDIAS MARGINALES ESTIMADAS } \\
\hline \multirow{2}{*}{ Color_Auxiliar } & Media & \multirow{2}{*}{ Error típico } & \multicolumn{2}{|c|}{ Intervalo de confianza 95\% } \\
\cline { 4 - 5 } & & & Límite inferior & Límite superior \\
\hline $\mathbf{1}$ & $\mathbf{2 , 6 8 8}$ &, 117 & 2,451 & 2,924 \\
\hline $\mathbf{2}$ & 1,799 &, 093 & 1,612 & 1,986 \\
\hline $\mathbf{3}$ & 1,878 &, 122 & 1,633 & 2,124 \\
\hline
\end{tabular}

\subsection{CUARTA HIPÓTESIS}

A partir de este apartado se consideran algunos efectos de interacción específicos entre los factores que han intervenido en el experimento. En particular, se procede a analizar la cuarta hipótesis de trabajo la cual plantea los efectos de interacción producidos entre los valores cromáticos base y auxiliar. Dicha hipótesis se expone en los siguientes términos:

$\mathrm{H}_{4}$ Cuando se combina en un envase el valor cromático base con el valor cromático auxiliar se identifica la tipología de producto.

Dado que el nivel de significación (sig.) relativo a la interacción entre los factores Color_Base y Color_Auxiliar es 0,00 se puede rechazar la hipótesis nula y, en consecuencia, concluir que se detectan diferencias significativas entre los diferentes tratamientos experimentales (Tabla 7). En este sentido, dichas diferencias son debidas a las combinaciones que se establecen entre los valores cromáticos base y auxiliar. Se puede aceptar la credibilidad de dicha hipótesis.

Asimismo es importante considerar la excelente potencia estadística del contraste $(1,00)$ la cual es superior a 0,80 .

Tabla 7. Valores estadísticos de significación y potencia de los contrastes relativos a la interacción entre los factores Color_Base y Color_Auxiliar.

\begin{tabular}{|l|c|c|c|c|c|c|c|}
\hline \multicolumn{7}{|c|}{ COLOR_BASE + COLOR_AUXILIAR } \\
\hline $\begin{array}{l}\text { Contrastes } \\
\text { multivariados }\end{array}$ & Valor & $\mathbf{F}$ & $\begin{array}{c}\text { GI de la } \\
\text { hipótesis }\end{array}$ & GI del error & Sig. & $\begin{array}{c}\text { Coeficiente } \\
\mathbf{r}^{2}\end{array}$ & $\begin{array}{c}\text { Potencia } \\
\text { observada }\end{array}$ \\
\hline Traza de Pillai &, 627 & 15,981 & 4,000 & 38,000 &, 000 &, 627 & $\mathbf{1 , 0 0 0}$ \\
\hline $\begin{array}{l}\text { Lambda } \\
\text { de Wilks }\end{array}$ &, 373 & 15,981 & 4,000 & 38,000 &, 000 &, 627 & $\mathbf{1 , 0 0 0}$ \\
\hline $\begin{array}{l}\text { Traza } \\
\text { de Hotelling }\end{array}$ & 1,682 & 15,981 & 4,000 & 38,000 &, 000 &, 627 & $\mathbf{1 , 0 0 0}$ \\
\hline $\begin{array}{l}\text { Raíz mayor } \\
\text { de Roy }\end{array}$ & 1,682 & 15,981 & 4,000 & 38,000 &, 000 &, 627 & $\mathbf{1 , 0 0 0}$ \\
\hline
\end{tabular}


Por otra parte, las medias marginales estimadas de la interacción factorial Color_Base y Color_Auxiliar indican que la media más alta $(4,317)$ corresponde a la combinación entre el valor cromático base 1 y el auxiliar 1 (Tabla 8). Las restantes medias han presentado unos valores muy inferiores. En consecuencia, dicha formulación cromática se manifiesta como indicativa de la tipología de producto: leche entera.

Tabla 8. Conjunto de medias obtenidas por la interacción factorial entre Color_Base y Color_Auxiliar.

\begin{tabular}{|c|c|c|c|c|c|}
\hline \multicolumn{6}{|c|}{ MEDIAS MARGINALES ESTIMADAS } \\
\hline \multirow{2}{*}{ Color_Base } & \multirow{2}{*}{ Color_Auxiliar } & \multirow{2}{*}{ Media } & \multirow{2}{*}{ Error típico } & \multicolumn{2}{|c|}{ Intervalo de confianza al $95 \%$} \\
\hline & & & & Límite inferior & Límite superior \\
\hline \multirow{3}{*}{1} & 1 & 4,317 & ,090 & 4,128 & 4,507 \\
\hline & 2 & 2,325 & ,172 & 1,978 & 2,673 \\
\hline & 3 & 2,460 & ,179 & 2,098 & 2,822 \\
\hline \multirow{3}{*}{2} & 1 & 1,833 & , 180 & 1,469 & 2,198 \\
\hline & 2 & 1,476 & ,090 & 1,295 & 1,657 \\
\hline & 3 & 1,516 &, 116 & 1,282 & 1,750 \\
\hline \multirow{3}{*}{3} & 1 & 1,913 & ,170 & 1,569 & 2,257 \\
\hline & 2 & 1,595 & ,093 & 1,408 & 1,782 \\
\hline & 3 & 1,659 & 133 & 1,391 & 1,927 \\
\hline
\end{tabular}

\subsection{Quinta hipótesis}

En último lugar, se procede a analizar la quinta hipótesis de trabajo la cual plantea los efectos de interacción producidos entre la estructura del envase y los valores cromáticos base y auxiliar. Dicha hipótesis se expone en los siguientes términos:

$\mathrm{H}_{5}$ Cuando se combina la estructura del envase con los valores cromáticos base y auxiliar se identifica la tipología de producto.

Dado que el nivel de significación ( $\mathrm{sig}$.) relativo a la interacción entre los factores Estructura,CColor_Base y Color_Auxiliar es 0,244 se tiene que aceptar la hipótesis nula y, en consecuencia, concluir que no se detectan diferencias estadísticamente significativas entre los diferentes tratamientos experimentales (Tabla 9). En este sentido, no se manifiestan diferencias lo suficientemente relevantes cuando intervienen 
conjuntamente las tres variables independientes. Por tanto, no se puede aceptar la credibilidad de dicha hipótesis.

Asimismo es importante considerar la baja potencia estadística del contraste $(0,526)$ la cual es muy inferior a 0,80 . En esta circunstancia, la probabilidad de cometer un error Tipo II es muy alta.

Por otra parte, las medias marginales estimadas de la interacción factorial Estructura, Color_Base y Color_Auxiliar (Tabla 10) indican que la media más alta $(4,524)$ corresponde a la combinación entre la estructura de la maqueta $\mathrm{B}$, el valor cromático base 1 (blanco) y el auxiliar 1 (azul oscuro). A pesar de ello, no se observan diferencias importantes respecto de las maquetas A y $\mathrm{C}$ dado que las medias en ambos casos son sólo ligeramente inferiores (4,167 y 4,262 respectivamente).

De acuerdo con estos resultados, se pone de manifiesto que la influencia del factor Estructura no ha sido lo suficientemente relevante en la constitución del código visual. Aunque las medias obtenidas para los tratamientos visuales MAB1A1 (Figura 4), MBB1A1 (Figura 5) y MCB1A1 (Figura 6) sean altas, los valores son muy similares entre sí y, en consecuencia, no se establece una diferencia estadísticamente evidente. Es por esta razón -la igualdad estadística de las medias- que no se puede rechazar, en este caso, la hipótesis nula. Sin embargo, sí que se ha encontrado suficiente evidencia en el hecho de que el código visual se circunscriba al ámbito cromático.

Tabla 9. Valores estadísticos de significación y potencia de los contrastes relativos a la interacción entre los factores Estructura, Color_Base y Color_Auxiliar.

\begin{tabular}{|l|c|c|c|c|c|c|c|}
\hline \multicolumn{7}{|c|}{ ESTRUCTURA + COLOR_BASE + COLOR_AUXILIAR } \\
\hline $\begin{array}{l}\text { Contrastes } \\
\text { multivariados }\end{array}$ & Valor & $\mathbf{F}$ & $\begin{array}{c}\text { GI de la } \\
\text { hipótesis }\end{array}$ & $\begin{array}{c}\text { GI del } \\
\text { error }\end{array}$ & Sig. & $\begin{array}{c}\text { Coeficiente } \\
\mathbf{r}^{2}\end{array}$ & $\begin{array}{c}\text { Potencia } \\
\text { observada }\end{array}$ \\
\hline Traza de Pillai &, 244 & 1,371 & 8,000 & 34,000 &, 244 &, 244 &, $\mathbf{5 2 6}$ \\
\hline $\begin{array}{l}\text { Lambda } \\
\text { de Wilks }\end{array}$ &, 756 & 1,371 & 8,000 & 34,000 &, $\mathbf{2 4 4}$ &, 244 &, $\mathbf{5 2 6}$ \\
\hline $\begin{array}{l}\text { Traza } \\
\text { de Hotelling }\end{array}$ &, 323 & 1,371 & 8,000 & 34,000 &, $\mathbf{2 4 4}$ &, 244 &, $\mathbf{5 2 6}$ \\
\hline $\begin{array}{l}\text { Raíz mayor } \\
\text { de Roy }\end{array}$ &, 323 & 1,371 & 8,000 & 34,000 &, $\mathbf{2 4 4}$ &, 244 &, $\mathbf{5 2 6}$ \\
\hline
\end{tabular}

Figura 4: MAB1A1

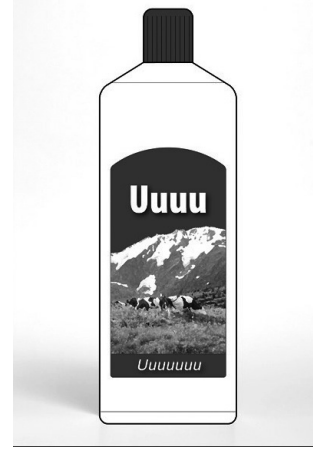

Figura 5: MBB1A1

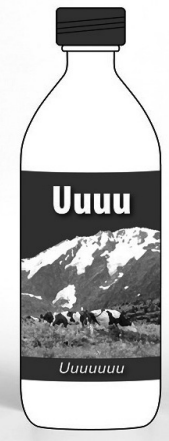

Figura 6: MCB1A1

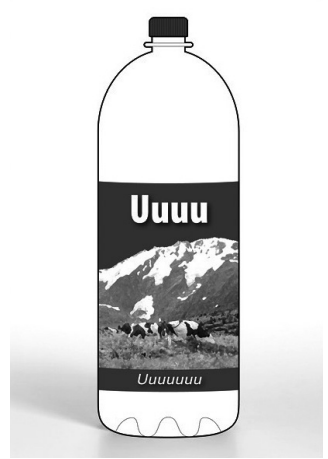


Tabla 10. Medias obtenidas por la interacción factorial entre Estructura, Color_Base y Color_Auxiliar.

\begin{tabular}{|c|c|c|c|c|c|c|}
\hline \multicolumn{7}{|c|}{ MEDIAS MARGINALES ESTIMADAS } \\
\hline \multirow{2}{*}{$\begin{array}{c}\text { Estructura } \\
\text { de la } \\
\text { maqueta }\end{array}$} & \multirow{2}{*}{$\begin{array}{c}\text { Color_ } \\
\text { Base }\end{array}$} & \multirow{2}{*}{$\begin{array}{l}\text { Color } \\
\text { Auxiliar }\end{array}$} & \multirow{2}{*}{ Media } & \multirow{2}{*}{$\begin{array}{l}\text { Error } \\
\text { típico }\end{array}$} & \multicolumn{2}{|c|}{$\begin{array}{c}\text { Intervalo de confianza } \\
\text { al } 95 \% \\
\end{array}$} \\
\hline & & & & & Límite inferior & Límite superior \\
\hline \multirow{9}{*}{ A } & \multirow{3}{*}{1} & 1 & 4,167 & ,136 & 3,892 & 4,441 \\
\hline & & 2 & 1,976 & ,182 & 1,609 & 2,344 \\
\hline & & 3 & 1,976 & , 175 & 1,622 & 2,330 \\
\hline & \multirow{3}{*}{2} & 1 & 1,714 & , 191 & 1,329 & 2,099 \\
\hline & & 2 & 1,452 & ,114 & 1,222 & 1,683 \\
\hline & & 3 & 1,357 & , 127 & 1,101 & 1,613 \\
\hline & \multirow{3}{*}{3} & 1 & 1,810 & ,184 & 1,437 & 2,182 \\
\hline & & 2 & 1,476 & 109 & 1,256 & 1,696 \\
\hline & & 3 & 1,643 & ,159 & 1,321 & 1,964 \\
\hline \multirow{9}{*}{ B } & \multirow{3}{*}{1} & 1 & 4,524 & ,133 & 4,255 & 4,792 \\
\hline & & 2 & 2,429 & ,196 & 2,032 & 2,825 \\
\hline & & 3 & 2,857 & ,222 & 2,408 & 3,306 \\
\hline & \multirow{3}{*}{2} & 1 & 2,000 & ,204 & 1,587 & 2,413 \\
\hline & & 2 & 1,500 & ,124 & 1,249 & 1,751 \\
\hline & & 3 & 1,738 & ,149 & 1,438 & 2,039 \\
\hline & \multirow{3}{*}{3} & 1 & 2,190 & ,221 & 1,743 & 2,638 \\
\hline & & 2 & 1,619 & ,136 & 1,344 & 1,894 \\
\hline & & 3 & 1,762 & 180 & 1,399 & 2,125 \\
\hline \multirow{9}{*}{ C } & \multirow{3}{*}{1} & 1 & 4,262 & ,156 & 3,946 & 4,578 \\
\hline & & 2 & 2,571 & ,224 & 2,119 & 3,023 \\
\hline & & 3 & 2,548 & ,216 & 2,111 & 2,984 \\
\hline & \multirow{3}{*}{2} & 1 & 1,786 & ,194 & 1,393 & 2,178 \\
\hline & & 2 & 1,476 & ,119 & 1,235 & 1,717 \\
\hline & & 3 & 1,452 & ,128 & 1,193 & 1,712 \\
\hline & \multirow{3}{*}{3} & 1 & 1,738 & 187 & 1,361 & 2,115 \\
\hline & & 2 & 1,690 & 158 & 1,371 & 2,010 \\
\hline & & 3 & 1,571 & 149 & 1,270 & 1,873 \\
\hline
\end{tabular}

\section{Conclusiones}

De acuerdo con los datos obtenidos, se han detectado diferencias estadísticamente significativas que ponen de manifiesto que las variables Estructura, Color_Base y Color_Auxiliar actúan, en principio, como componentes activos del código visual. 
En primer lugar, se ha podido constatar -según los efectos principales analizados- que los contrastes estadísticos confirman que entre los tratamientos visuales se han observado diferencias relevantes en relación a la estructura del envase. En este sentido, la maqueta B ha sido la opción preferida para identificar la tipología de producto (leche).

En cuanto a la variable Color_Base, los contrastes estadísticos confirman que entre los valores cromáticos utilizados se establecen diferencias significativas. En este caso, la diferencia entre medias muestra que el valor cromático base 1 -cuando la botella de leche es blanca- es el que mejor congenia con dicha tipología de producto.

Por otra parte, los contrastes estadísticos relativos a la variable Color_Auxiliar indican también que entre dichos valores cromáticos se evidencian diferencias significativas. En este punto, se pone de manifiesto que el valor cromático auxiliar permite identificar la tipología de leche. Es decir, según los resultados obtenidos, los sujetos experimentales asocian el valor cromático auxiliar 1 (azul) con la leche entera.

En segundo lugar, se ha podido constatar -según los efectos de interacción factorial- que los contrastes estadísticos entre Color_Base y Color_Auxiliar ponen de manifiesto una diferencia significativa de medias entre los tratamientos experimentales. Dicha diferencia emerge cuando se combina siempre el valor cromático base 1 (blanco) con el valor cromático auxilar 1 (azul). Esto ha permitido inferir que existe un código cromático específico para identificar la tipología de producto: leche entera.

Con respecto a la interacción factorial Estructura,CColor_Base y Color_Auxiliar, los contrastes estadísticos no consiguen valores de significación aceptables. Es decir, la intervención de la variable Estructura no ha tenido efectos relevantes sobre los sujetos experimentales y, por lo tanto, su influencia como componente activo del código visual no se ha podido constatar.

Los resultados de las pruebas de contraste indican que el código es fundamentalmente cromático, dado que la intervención de las variables Color_Base y Color_Auxiliar relega o anula el hipotético efecto provocado por la estructura del envase. Parece, por tanto, que el efecto principal del factor Estructura pierde potencia comunicativa cuando interactúa con los restantes factores.

En este caso, se pueden contemplar tres posibles explicaciones. Primera, que los niveles del factor Estructura no hayan tenido un mayor contraste visual que permita la fácil diferenciación de las maquetas. Segunda, que no exista una estructura de envase prototípica para determinar la identidad tipológica del producto. Tercera, considerar que la participación de una mayor muestra de sujetos experimentales hubiera podido incrementar el nivel de significación del contraste no superado.

Para terminar, a partir de este trabajo se abren nuevas líneas de investigación que permitirán, por una parte, estudiar los umbrales perceptivos en relación a las estructuras de los envases pero, al mismo tiempo, analizar el código cromático de los productos o, incluso, la forma tipográfica como probable componente del código visual. 


\section{Referencias bibliográficas}

AAKER, David; MYERS, John (1984). Management de la publicidad. Perspectivas prácticas. Barcelona: Editorial Hispano Europea.

ALBA, Joseph W.; HUTCHINSON, J. Wesley (1987). Dimensions of consumer expertise. En: Journal of Consumer Research, vol. 13, pp. 411-453.

AMBROSE, Gavin; HARRIS, Paul (2011). Packaging de la marca. Barcelona: Parramón Ediciones.

ARNHEIM, Rudolf (2005). Arte y percepción visual. Madrid: Alianza Editorial.

BASSAT, Luís (1994). El libro rojo de la publicidad. Barcelona: Ediciones Folio.

BASU, Kunal (1993). Consumer's categorization processes: an examination with two alternative methodological paradigms. En: Journal of Consumer Psychology, vol. 2, pp. 97-121.

BERKOWITZ, Marvin (1987). Product shape as a design innovation strategy. En: The Journal of Product Innovation Management, núm. 4, pp. 274-283.

BERTALANFFY, Ludwing von (1981). Teoría general de los sistemas. Fundamentos, desarrollo, aplicaciones. Madrid: Fondo de Cultura Económica.

BLOCH, Peter H. (1995). Seeking the ideal form: product design and consumer response. En: Journal of Marketing, vol. 59, Issue. 3, pp. 16-29.

BUNGE, Mario (1989). La investigación científica. Barcelona: Ariel.

CALVER, Giles (2004). ¿Qué es el packaging? Barcelona: Gustavo Gili.

CAPELLA, Juli; ÚBEDA, Ramón (2003). Cocos, copias y coincidencias. Barcelona: Electa.

CERVERA, Ángel Luis (2003). Envase y embalaje, la venta silenciosa. Madrid: ESIC.

COLET, Jordi (2012). La identidad visual de los envases. Una aproximación a la función publicitaria del packaging. [Tesis doctoral en línea] Bellaterra: Universidad Autónoma de Barcelona. Disponible en http://www.tdx.cat/handle/10803/145037

CONNOLLY, A.; DAVIDSON, L. (1996). How does design affect decisions at point of sale? En: Journal of Brand Management, vol. 4, núm. 2, pp.100-107.

COSTA, Joan (2004). La imagen de marca. Barcelona: Ediciones Paidós.

CREUSEN, Mariëlle; SCHOORMANS, Jan (2005). The different roles of product appearance in consumer choice. En: The Journal of Product Innovation Management, vol. 22, pp. 63-81.

DEMBER, W. (1990). Psicologia de la percepción. Madrid: Alianza Editorial.

DONDIS, Donis (2004). La sintaxis de la imagen. Barcelona: Editorial Gustavo Gili.

DEFLEUR, Melvin; BALL-ROKEACH, Sandra (1982). Teorías de la comunicación de masas. Barcelona: Editorial Paidós.

ECO, Umberto (1972). La estructura ausente. Barcelona: Editorial Lumen.

- - (1977). Tratado de semiótica general. Barcelona: Editorial Lumen.

FESTINGER, Leon (1975). Teoría de la disonancia cognitiva. Madrid: Centro de Estudios Políticos y Constitucionales.

GARBER, Lawrence (1995). The package appearance in choice. En: Advances in Consumer Research, vol. 22, pp. 653-660.

HELLER, Eva (2005). Psicología del color. Barcelona: Gustavo Gili. 
HOYER, Wayne (1984). An examination of consumer decision making for a common repeat purchase product. En: Journal of Consumer Research, vol. 11, pp. 822-829.

IGARTUA, Juan José (2006). Métodos cuantitativos de investigación en comunicación. Barcelona: Editorial Bosch.

LÁZARO, Patricia et al. (2007). La recepción, un límite a la creación. En: Trípodos. Barcelona: Servicio de Diseño y Publicaciones Blanquerna. Número extraordinario, pp. 685-704.

LOKEN, Barbara; WARD, James (1990). Alternative approaches to understanding the determinants of tipicality. En: Journal of Consumer Research, 1990, vol. 17, pp. 111-126.

MAEDA, John (2010). Las leyes de la simplicidad. Barcelona: Gedisa.

MARTÍNEZ, José Manuel (2010). La influencia del Aspecto en la eficiencia del mensaje gráfico publicitario. [Tesis doctoral en línea] Bellaterra: Universidad Autónoma de Barcelona. Disponible en http://hdl.handle.net/10803/4161

MOLES, Abraham (1976). Teoría de la información y percepción estética. Madrid: Ediciones Júcar, 1976.

MORGADO, Ignacio (2012). Cómo percibimos el mundo. Una exploración de la mente y los sentidos. Barcelona: Editorial Ariel.

PHILIPS, H.; BRADSHAW, R. (1993). How customers actually shop: customer interaction with the point of sale. En: Journal of the Market Research Society, vol. 35, núm. 1, pp. 51-62.

RETTIE, Ruth; BREWER, Carol (2000). The verbal and visual components of package design. En: Journal of Product \& Brand Management, vol. 9, núm. 1, pp. 56-70.

ROM, Josep (2002). Els fonaments del disseny gràfic. Barcelona: Trípodos.

ROSCH, Eleanor; MERVIS, Carolyn (1975). Family resemblances: studies in the internal structure of categories. En: Cognitive Psychology, vol. 7, pp. 573-605.

SAPERAS, Enric (1985). La sociología de la comunicación de masas en los Estados Unidos. Barcelona: Editorial Ariel.

SCHNAKE, Hugo (1990). El comportamiento del consumidor. México: Editorial Trillas.

SCHOORMANS, Jan; ROBBEN, Henry (1997). The effect of new package design on product attention, categorization and evaluation. En: Journal of Economic Psychology, vol. 18, pp. 271-287.

SIERRA, Benjamín; FALCES, Carlos (2001). El papel de la apariencia visual del diseño de los envases en el reconocimiento del producto, de la variedad y de la marca. En: RUIZ, Salvador; ALONSO, Javier. Experiencias y casos de comportamiento del consumidor. Madrid: ESIC, pp. 131-143.

STEWART, Bill (2008). Packaging. Manual de diseño y producción. Barcelona: Gustavo Gili.

TENA, Daniel (1998). La influencia de la composición gráfica en la elección de un bloque de texto escrito. [Tesis doctoral en línea] Bellaterra: Universidad Autónoma de Barcelona. Disponible en http://www.tdx.cat/handle/10803/4135

VERYZER, Robert (1995). The place of product design and aesthetics in consumer research. En: Advances in Consumer Research, vol. 22, pp. 641-645. 
VIDALES, María Dolores (2003). El mundo del envase. Manual para el diseño y producción de envases y embalajes. Barcelona: Editorial Gustavo Gili.

VIGLIETTI, M. (1975). La psicología de la forma y la Gestalt Theorie. Barcelona: Ediciones Don Bosco.

VIÑOLAS, Joaquim (2005). Diseño ecológico. Barcelona: Blume.

WARD, James; LOKEN, Barbara (1988). The generality of typicality effects on preference and comparison: an exploratory test. En: Advances in Consumer Research, vol. 15, pp. 55-61. 